\title{
YEMENI EXPERIENCE OF BUILDING RESIDENTIAL QUARTERS FOR LOW INCOME INDIVIDUALS IN THE METROPOLITAN OUTSKIRTS (MUKALLA AND ADEN: CASE STUDY)
}

\section{Khaled Nasser Barashed and Aymen Essa}

Department of Architecture, Faculty of Engineering

(Recieved August 12, 2007 Accepted November 4, 2007)

The increase in population in the past few decades all over a large number of underdeveloped world lead to the augmentation of population crisis, especially among the low income population categories. This urged many governments of such countries including the governments of our Arabian area to adopt special residential policies for those categories to alleviate the strain of this problem.

Ever since the beginning of twentieth century, Yemen (especially its southern part) had gone through many experiences in erecting residential units for the low income individuals throughout metropolitan outskirts around its principal cities making best use of the universal expertise in this field. Despite the serious attempt to control the aggravation of the population problem through such residential units, yet, due to its failure to be based upon authentic accurate studies on the one hand, and due to the lack of participation of the popular classes in the decision making process at any stage at all on the other hand, it transformed these residential units into forming an element of expulsion for the population for many long years for the unavailability of a great number of services around them and also due to the random construction that spread throughout its streets and buildings later on because they were neither culturally nor socially suitable for the inhabitants.

The research aims at introducing some of these experiences, discussing them, analyzing them, and assessing them, along with trying to derive the main features by comparing them with selected styles of conventional construction. The study will concentrate upon such residential unites at the cities of Aden and Mukalla by the discussing the various advantages and disadvantages of those projects and the extent of the cultural and the social effects of such projects upon the inhabitants in order to set a future criteria for certain residential units that may satisfy the requirements for the population and delimit the random building phenomenon and the visual pollution. 
الملامح العمرانية لتجربة اليمن في بناء الأحياء السكنية لذوي الاخل المحدود في ضواحي المدن (مدينتي المكلا وعدن دراسة حالة الئة)

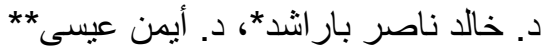

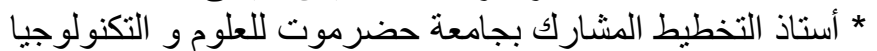 \\ * مدرس التخطيط بجامعة أسيوط، جمهورية مصر العربية ومعار للعمل كأستاذ مساعد في جامعة جئة

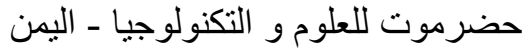 \\ Barashed@hotmail.com
}

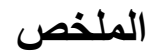

لقد أدى زيادة السكان في العقود القليلة الماضية في كثير من دول العالم النامي إلى تفاقم أزمة المساكن -

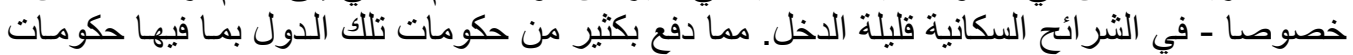

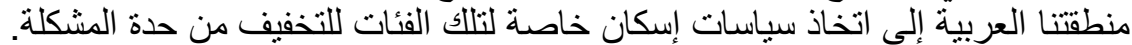

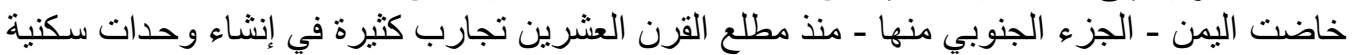

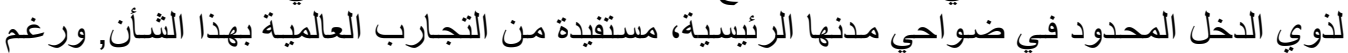

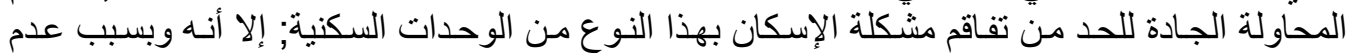

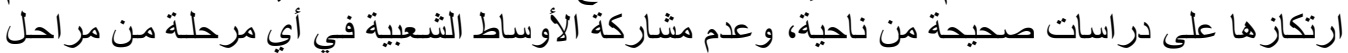

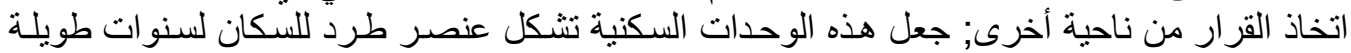

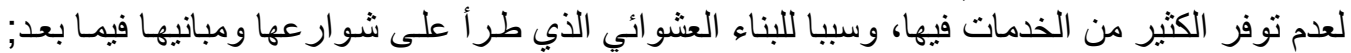
لعدم تلائمها ثقافيا و اجتماعيا مع السكان.

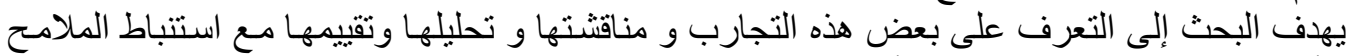

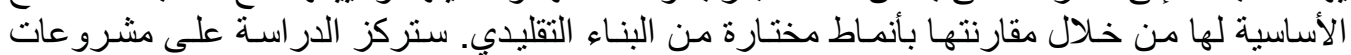

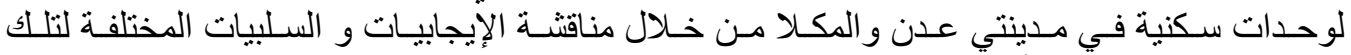

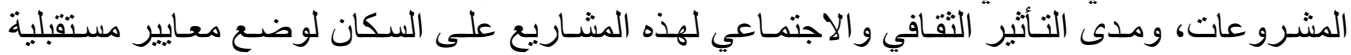

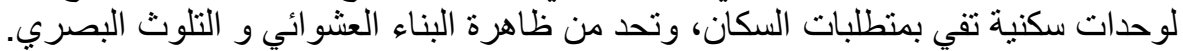

كلمات دالة: إسكان، الدخل المحدود، ضواحي المدن، اليمن،

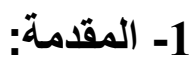

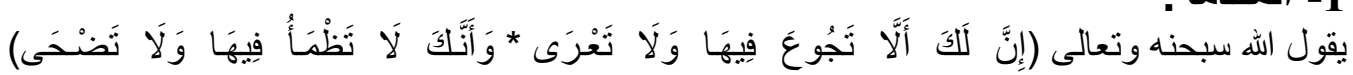

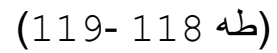

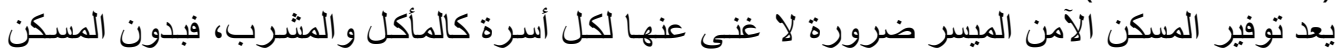

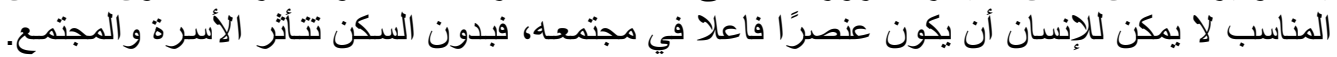

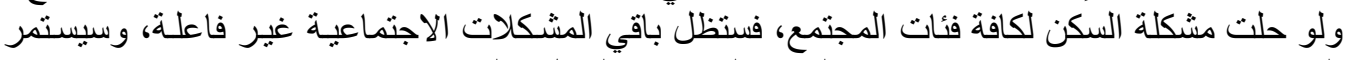

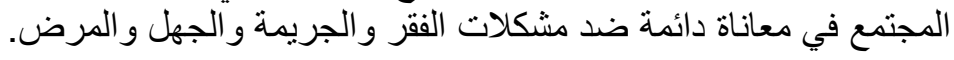

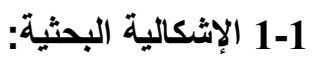

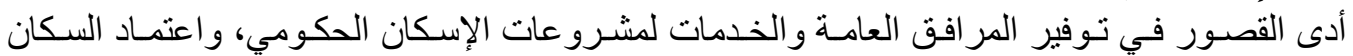

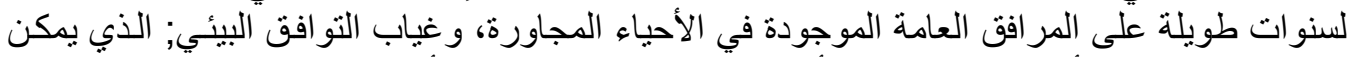

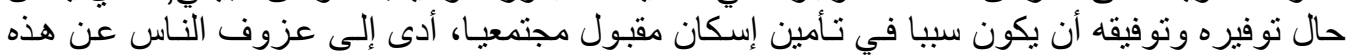

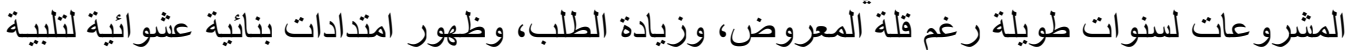


يهدف البحث إلى التعرف على بعض تجارب إنشاء وحدات سكنية لذوي الاخل المحدود في ضواحي

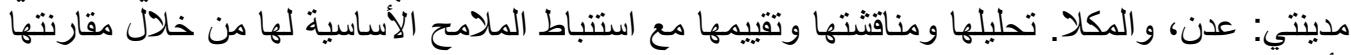

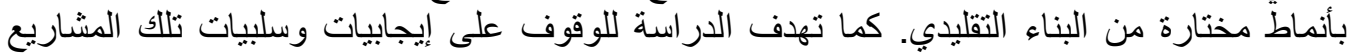

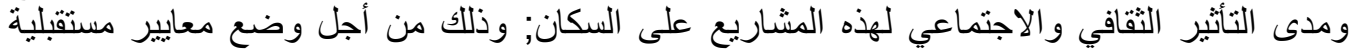
لوحدات سكنية تفي بمنطلبات السكان وتحد من ظاهرة البناء العشوائي و التلوث الثان البصري. 3-1

اعتمدت هذه الورقة على الدراسة النظرية، والتحليلية لمشناريع إسكانية مختارة في مدينتي: عدن،

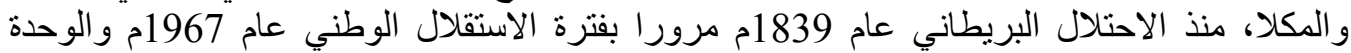

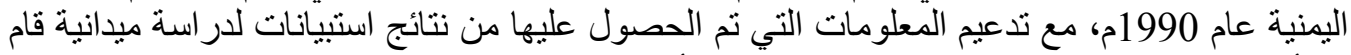

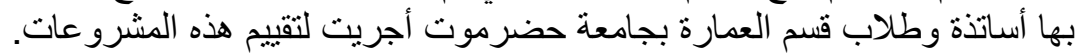

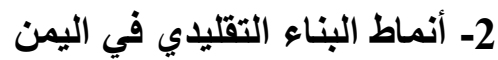

أفرزت طبو غرافية اليمن المختلفة تتوع مناخيا متباينا بمصادره الطبيعية و كذا من مواد البياء البناء المتاحة للتشييد، و قد ساهم ذلك التباين في الطبوغر افية، و المناخ و المصادر إلى إلى اختلاف في توزيع السكان،

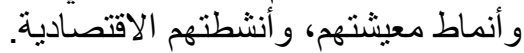

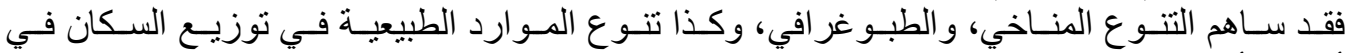

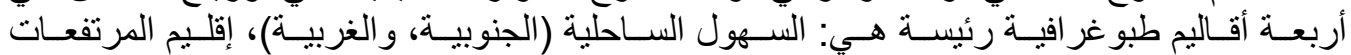

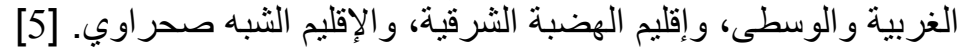

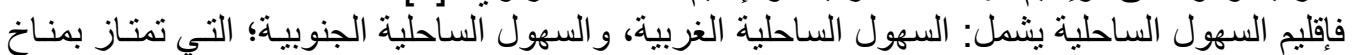
حار رطب صيفا يمبل إلى الاعتدال شتاء. أما إقليم المرتفعات الغربية، و الوسطى فئه فئع في القسم الغربي

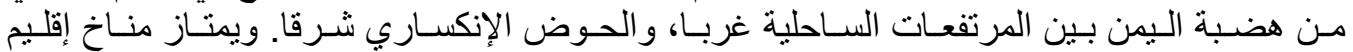

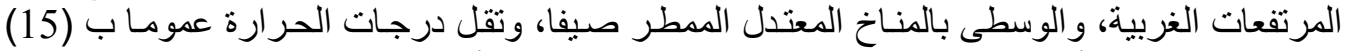

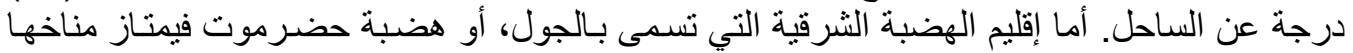

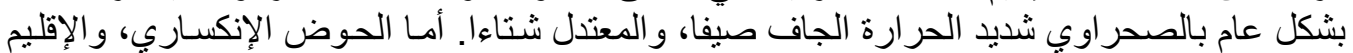

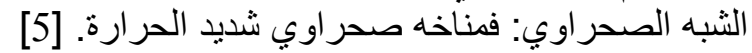

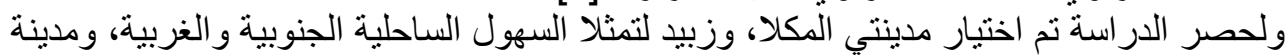

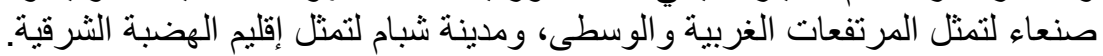




\begin{tabular}{|c|c|c|c|c|}
\hline الهضبة الثرقية & المرتفعات الغربية والوسطى & \multicolumn{2}{|c|}{ السهول الساحلية } & ال الإقليم \\
\hline شبام & صنعاء & زبيد & المكلا & \\
\hline حتى 1200م فوق سطح البحر & حتى 3660م فوق سطح البحر & & 1500-1م فوق سطح البحر & الارتفاع \\
\hline شبطى بارد شتاءً، جاف، حار صيفاً وحار & سطو عندل شيفي منارد شتاءً، جاف & شמ & حار (شديد)، رطوبة عالي & المناخ \\
\hline مغلق(يمتد رأسياً) & مغلق (يمتد رأسياً) & حر مفتوح (يمتد أفقياً) & مغلق (يمتد رأسياً) & أسلوب البناء \\
\hline 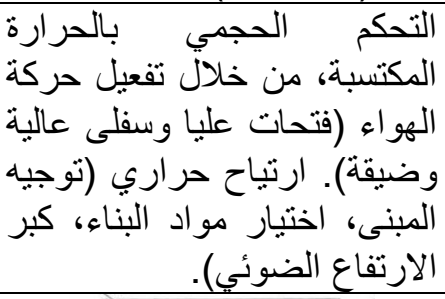 & 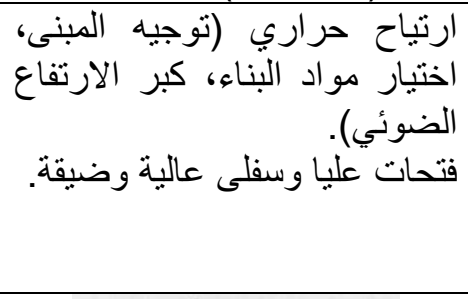 & 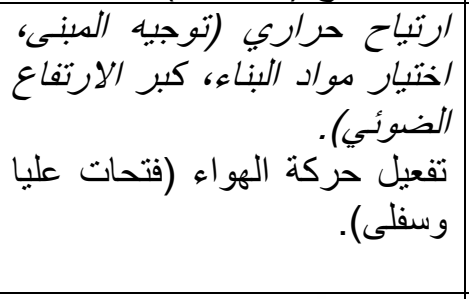 & 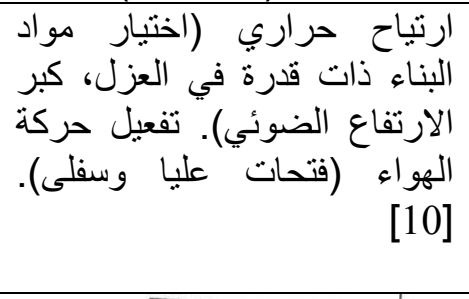 & التحكم البيئي على \\
\hline (1) & is & & STrobe & المسقط \\
\hline 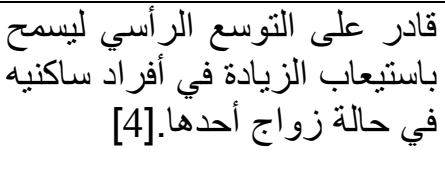 & 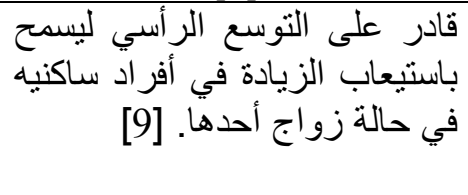 & 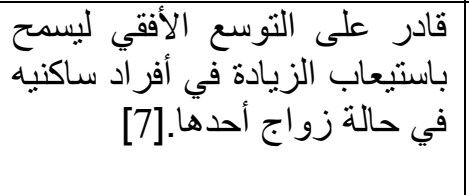 & 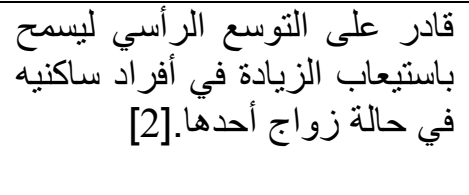 & تلمبط التصنيم السكني \\
\hline
\end{tabular}




\begin{tabular}{|c|c|c|c|c|}
\hline 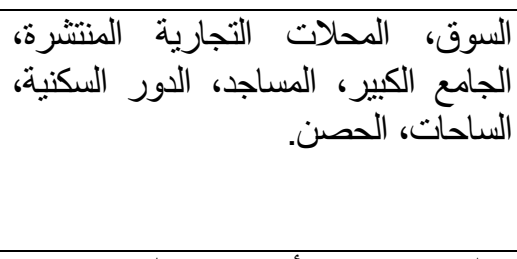 & 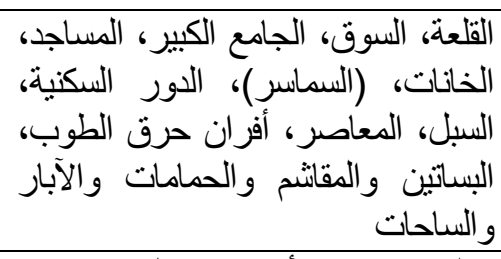 & 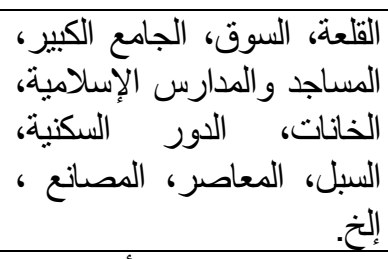 & 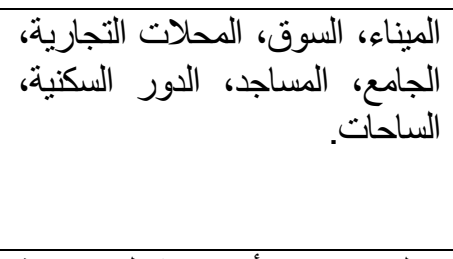 & 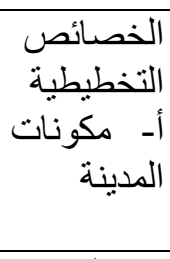 \\
\hline 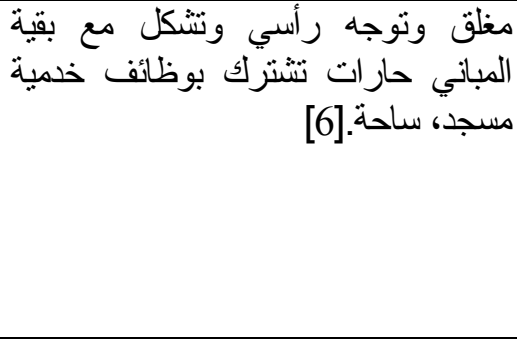 & 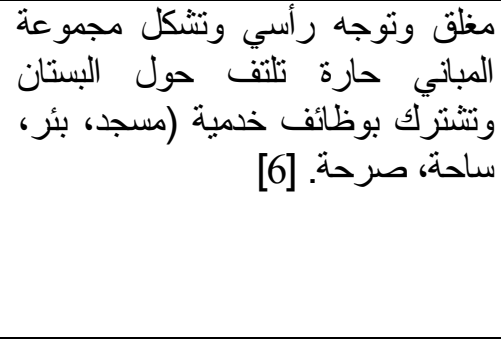 & 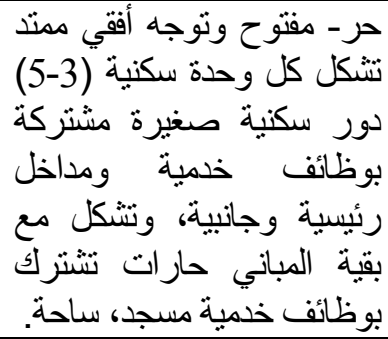 & 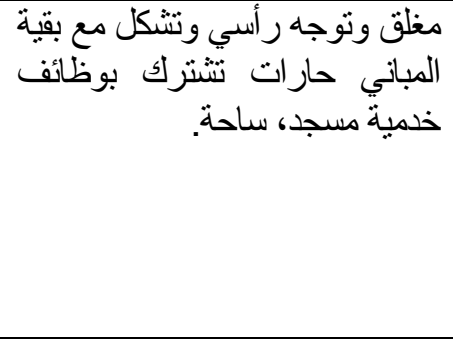 & بـ- التكوين \\
\hline 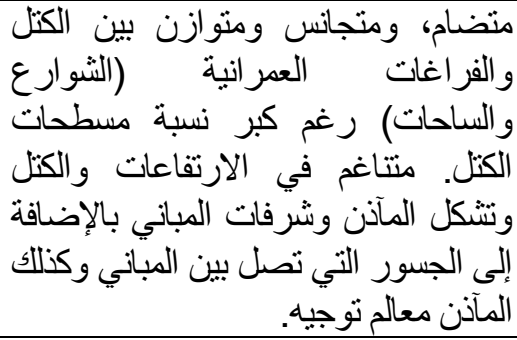 & 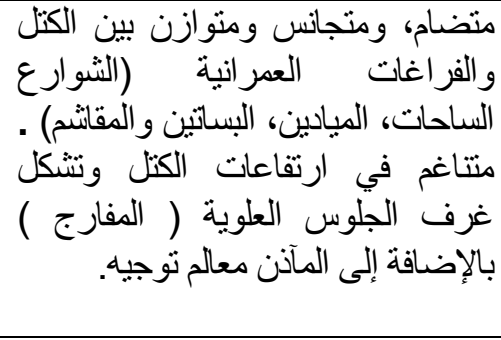 & 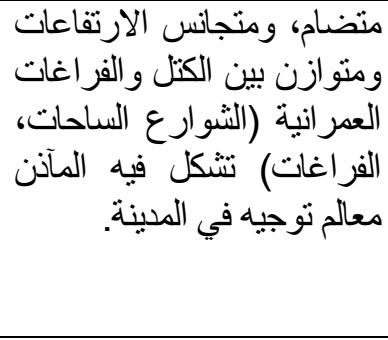 & 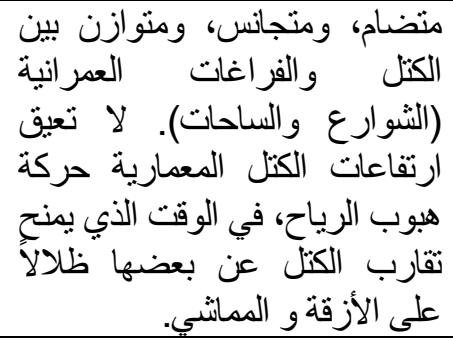 & النسيج \\
\hline شاحات صغيرة وضوية تربط مناطقة الملينة عبر & 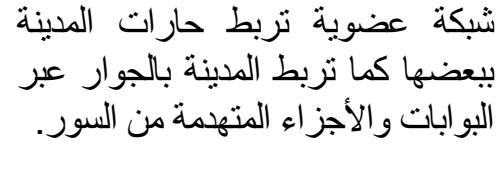 & 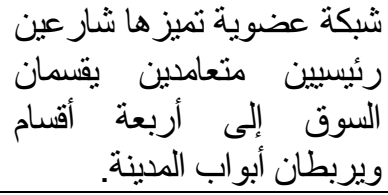 & 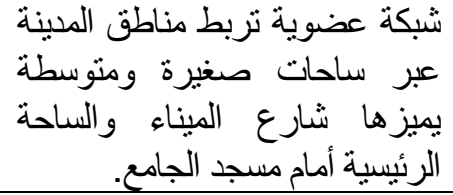 & 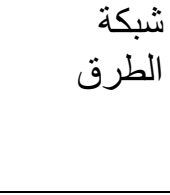 \\
\hline
\end{tabular}




\section{3- تجرية الإسكان الثُبي لذوي الدخل المحلود في النصف الأول من القرن العثرين- فترة الاحتلال:}

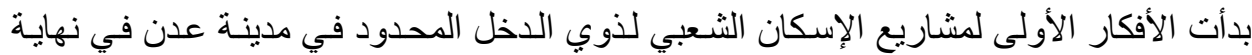

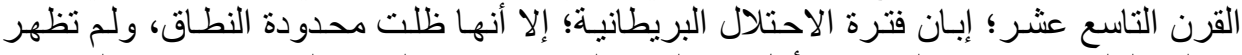

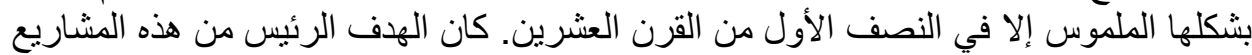

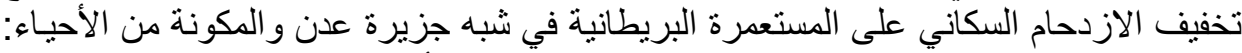

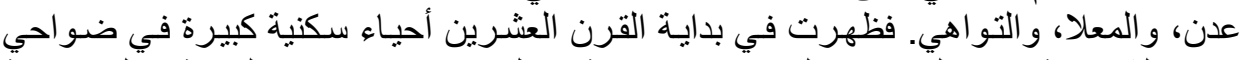

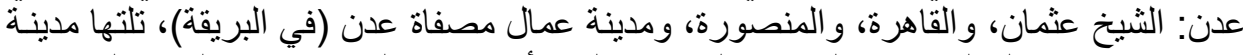

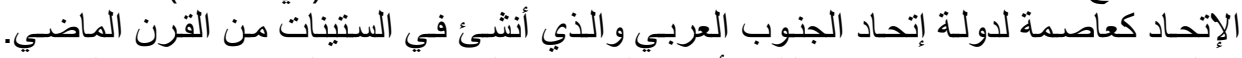

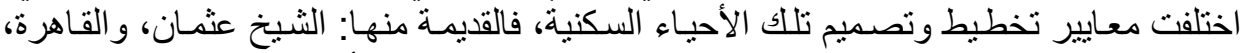

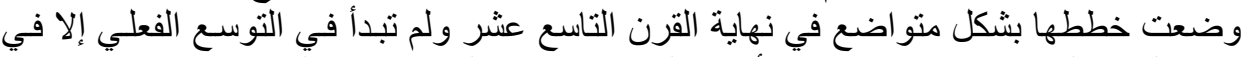

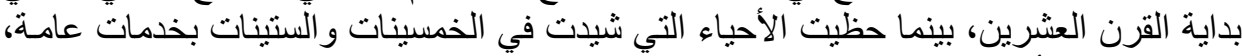

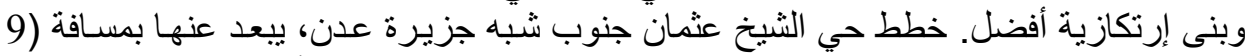

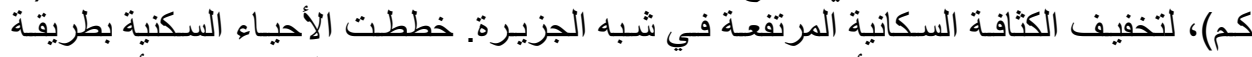

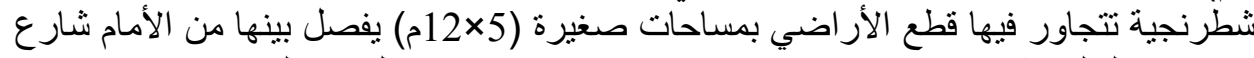

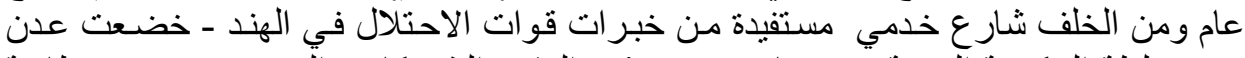

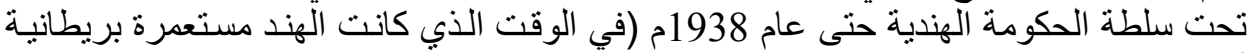

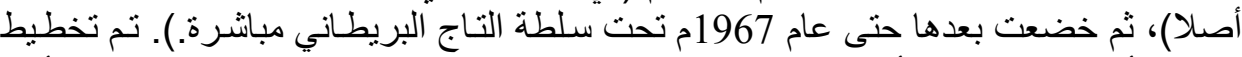

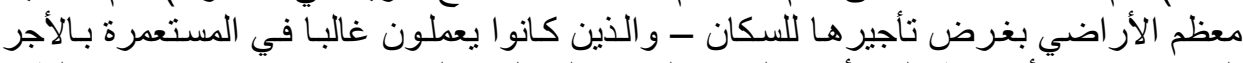

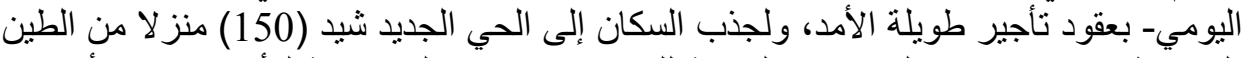

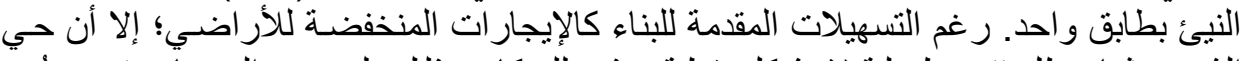

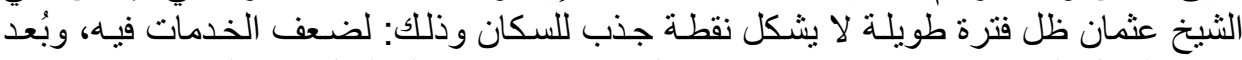

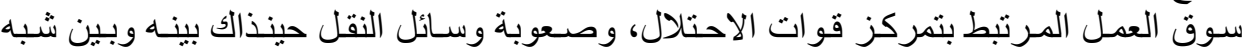

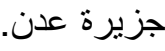
وفي منتصف الخمسينات من القرن الماضي أنشئ حي المنصسورة متاخما للثيخ عثمان، و القاهرة.

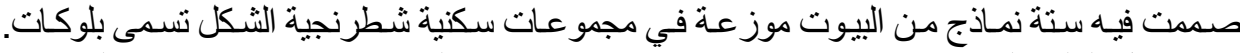

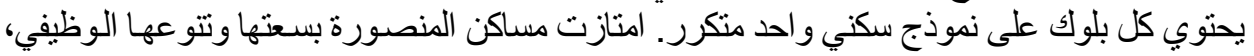

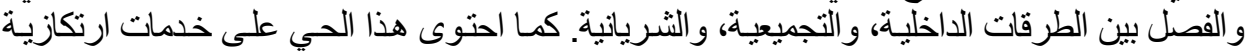

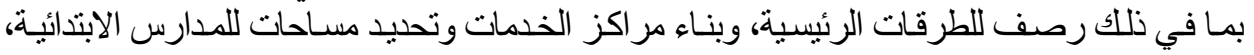

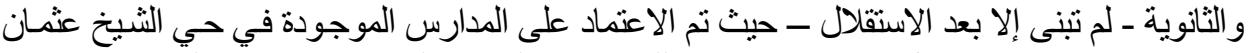

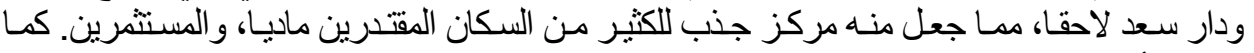

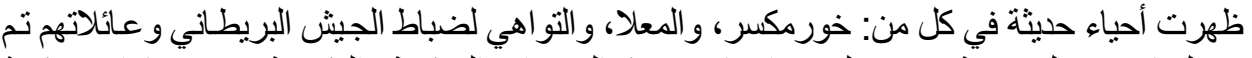

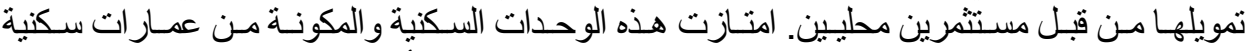

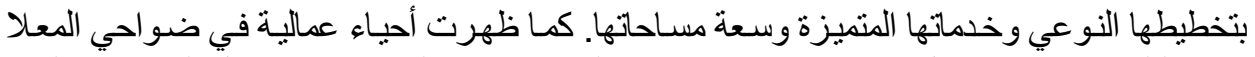

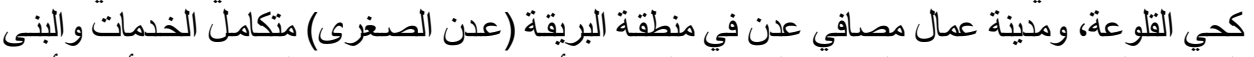

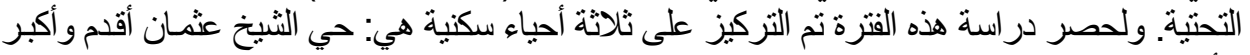

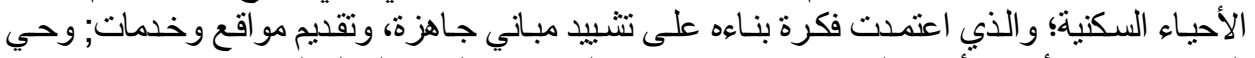

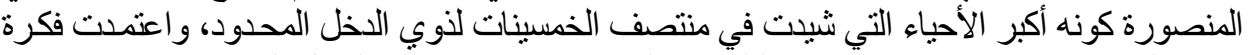

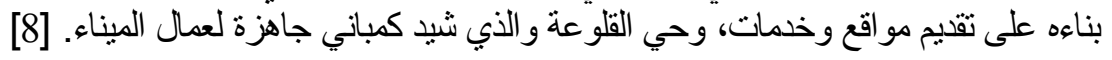


1-3 التحليل المعماري لمشاريع الإسكان في مدينة عدن (فترة الاحتلال):

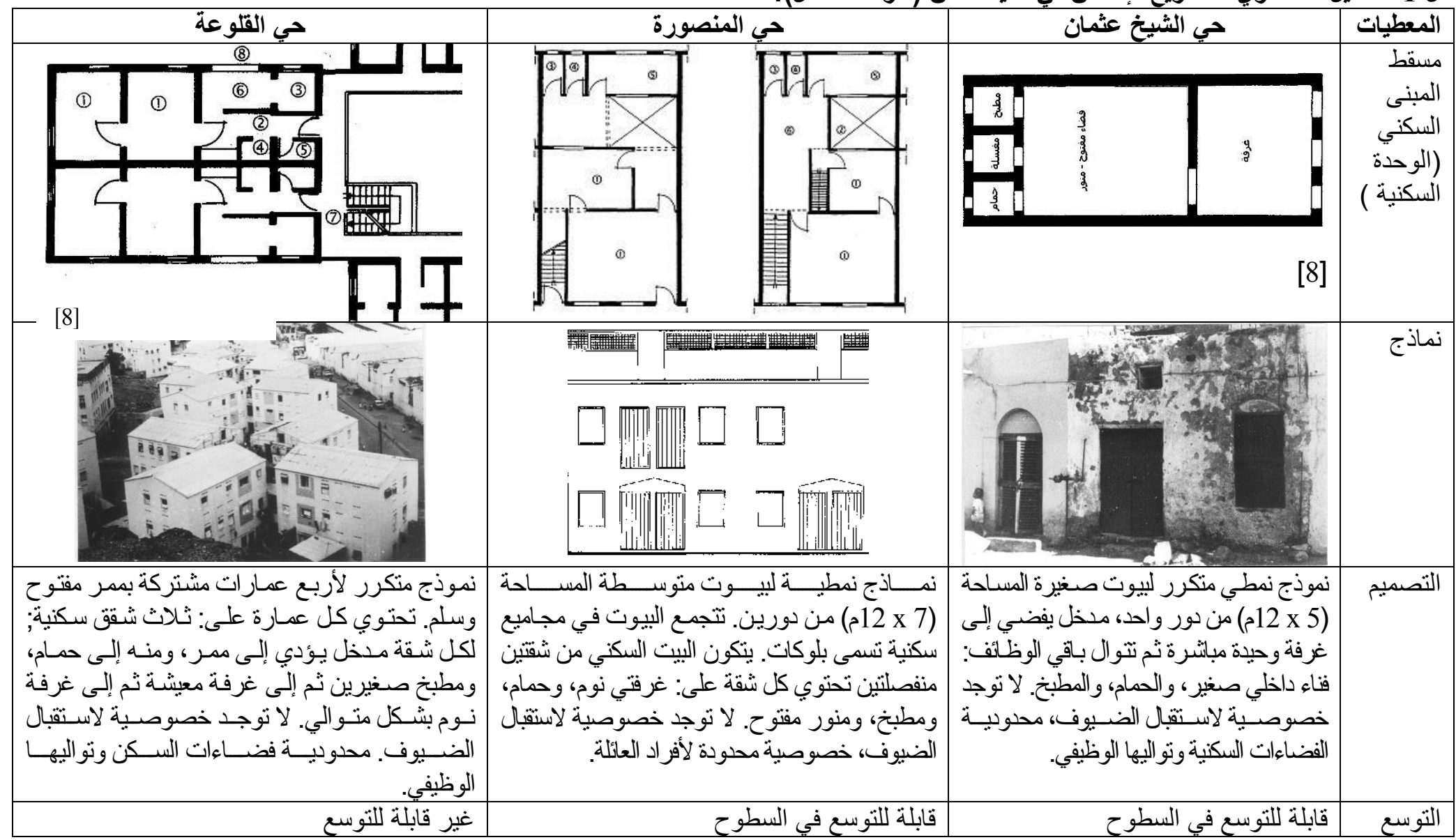




\begin{tabular}{|c|c|c|c|}
\hline و تعدي على في الأدواء الشـارعلى العام (استحداث أحو اش & 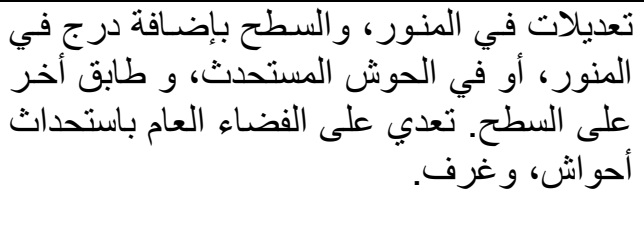 & 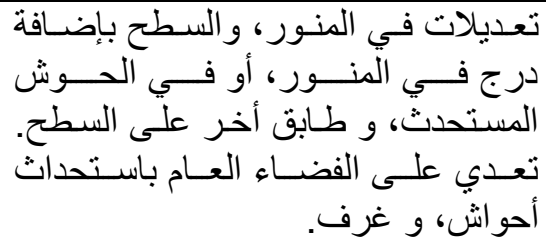 & و التعديلات \\
\hline 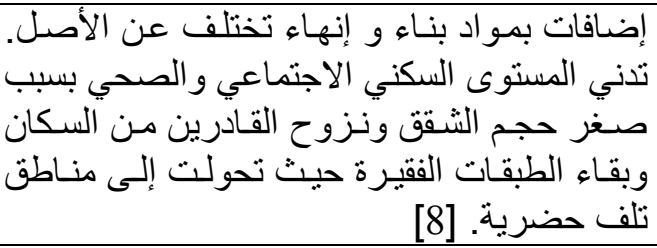 & 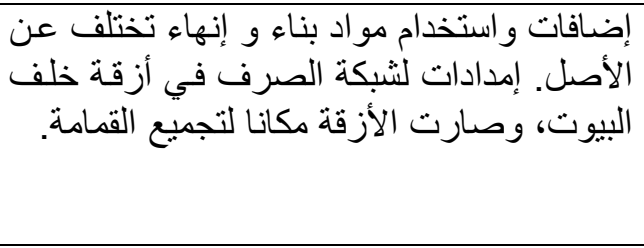 & 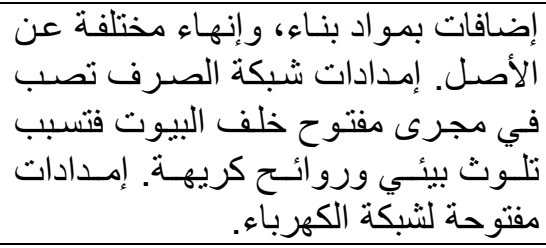 & 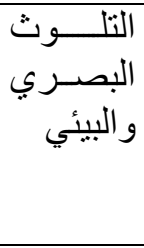 \\
\hline الثيخ إسحاق، الخساف (كريتر) & دار سعد، المنطقة الصناعية (الدرين) & 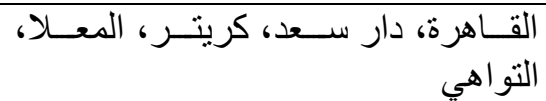 & مشاثلة مشـاريع \\
\hline
\end{tabular}

2-3 التحليل العمراني لمشاريع الإسكان في مدينة عدن (فترة الاحتلال):

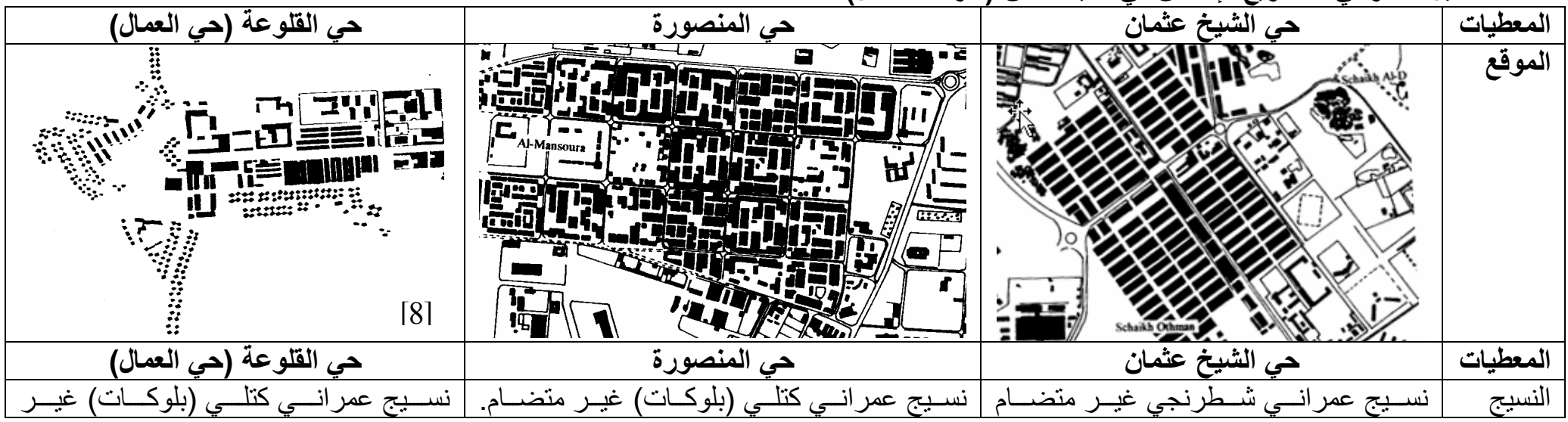




\begin{tabular}{|c|c|c|c|}
\hline 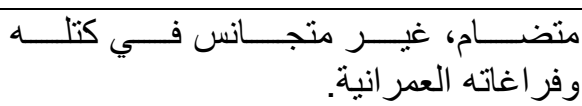 & متجانس في كتله وفر اغاته العمر انية. & 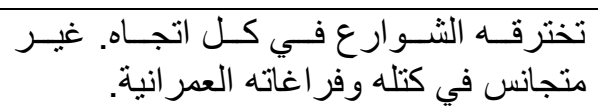 & العمر اني \\
\hline 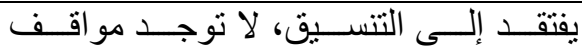 & يقتقـــ إلى التنسـيق، لا توجـد مو اقف للسـيار ات، & 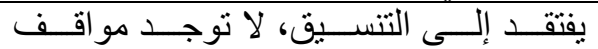 & فضاء \\
\hline للســـار ات، و لا أرصـفة للمشــاة. لا توجـــ & ولا أرصـــفة للمشـــاة، تـــــ الاســـنيلاء علـــى & للســــار ات، أرصـــفة ضــــقة ضــــــت & 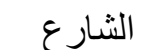 \\
\hline مســـاحات مخصصــــة للعـــب الأطفـــال، & 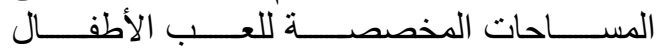 & 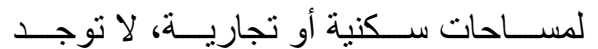 & \\
\hline مســـاحات ضـــقة بــين المبــانى ضــــت & و المســـاحات الخضــــر اء للأغـــر اض الســــنية & مســاحات مخصصـــة للعـــب الأطفـــال، & \\
\hline 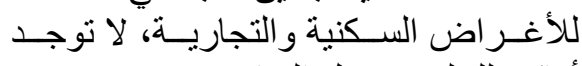 & 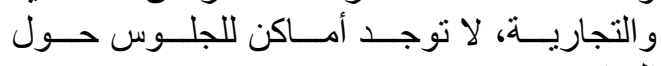 & مســاحات خضــر اء محدودة جـدا، لا توجـد & \\
\hline أماكن للجلوس حول المباني. & 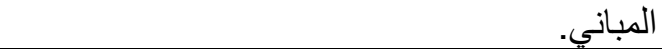 & أماكن للجلوس حول المباني. & \\
\hline 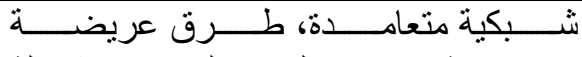 & شـبكية متعامـدة، طـرق مستققيمة تحبط بالأحيـاء & شـــكية متعامــة، طـرق مسـتقيمة تختـرق & شبكة \\
\hline ومسـتقيمة تختـرق الحـي السـكني مشـكلة & السكنية مشكلة تقاطعات مرورية خطرة. & الحــي السـكني تشـجع على القيـادة بســرعة & 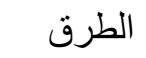 \\
\hline 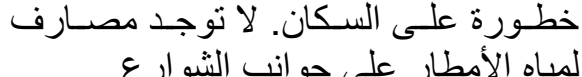 & 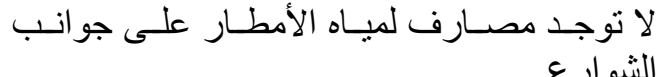 & 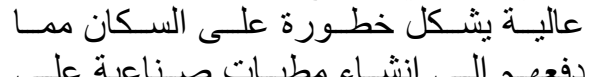 & \\
\hline 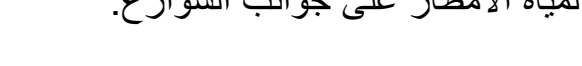 & & 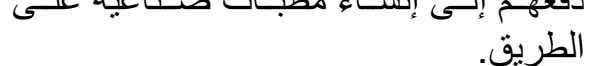 & \\
\hline تبعــــ المر اكـز و الأســواق عـن الحــي (4) & تبعــــ المر اكـز و الأســـواق عـن الحـي (500م ـ & المر اكـز و الأســـواق موجـودة وســـ الحــي & خـــــمات \\
\hline 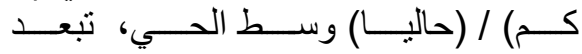 & 1 كـم) - تبعـــــــــارس الابتدائيسة (500م- 2 & ــ تبعــــــ المـــدارس الابتدائيــــة (400م- 1 & حضـــرية \\
\hline 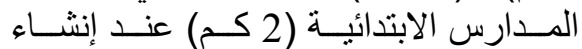 & كم) عنــد إنشــاء الحي / (حاليـا) (400م)، على & 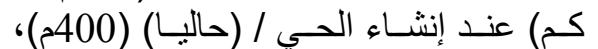 & (أســــواق, \\
\hline الحــي / (حاليــا) (500م)، ولكـن علــى & التلاميــذ أن يعبـرو ا عـــة شــوارع و وتقاطعــات & علتِى التلاميــذ أن يعبــرورا عـــة شــــوارع & مـــــدارس \\
\hline التلاميـــــ أن يعبـــروا شـــــوارع تجميعيـــة & & & ابتدائيــــــة، \\
\hline & & & \\
\hline & & & \\
\hline
\end{tabular}




\section{4- مشاريع الإسكان الحكومية لنوي الاخل المحلود في الجزء الجنوبي من اليمن (1967-1990):}

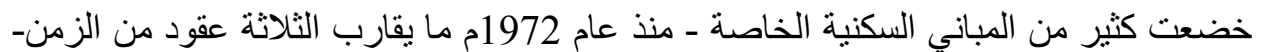
لقانون التأميم؛ فيما كان يعرف سابقا بجمهورية اليمن الديمقراطية الثعبية. وكان لتطبيق القانون

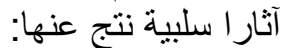
الأثر الأول: انهيار تام لدور القطاع الخاص في توفير السكن للمجتمع نظرًا لانعدام ثقته في إمكانية الحصول على عائد من استثمار أمو اله في مجال في الإل الإسكان.

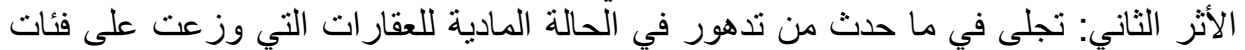

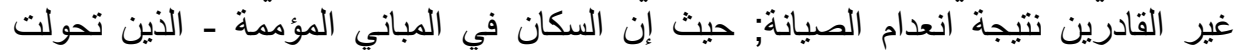

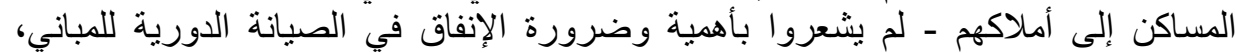

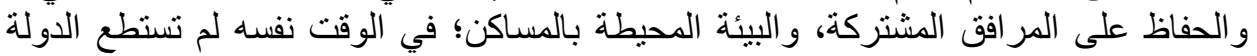

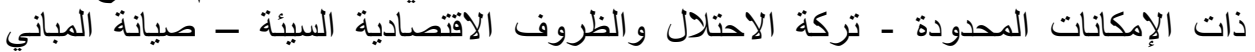

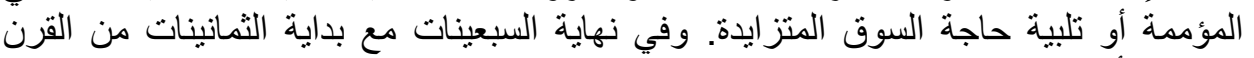

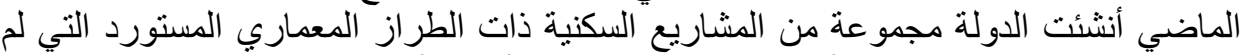

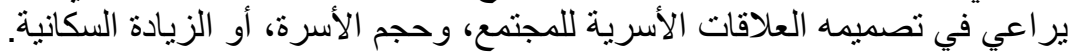

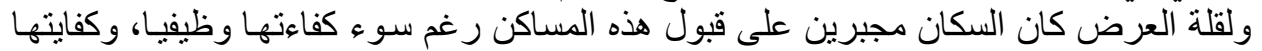

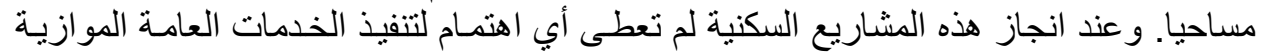

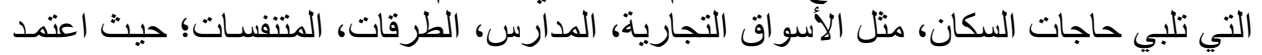

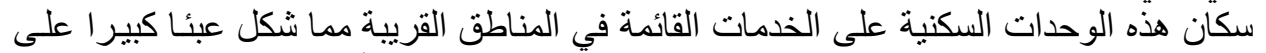
مر اكز خدمات المناطق القديمة، وكثير المن الجهد، والمشقة لسكان الأحباء الجديدة. [10]

\section{1-4 مشاريع الإسكان في مدينة عدن:}

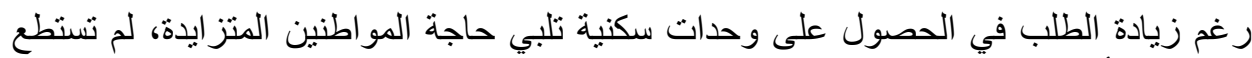

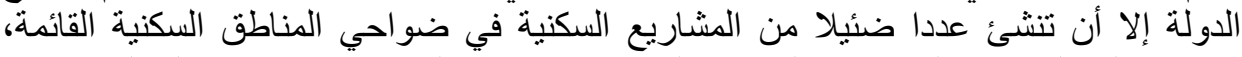

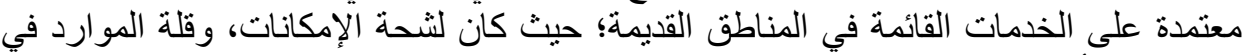

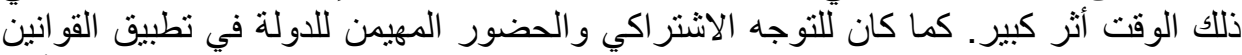

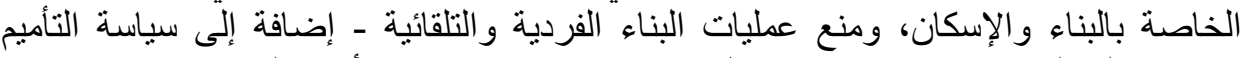

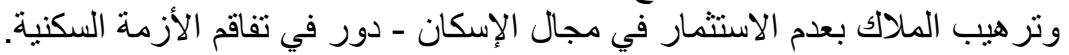

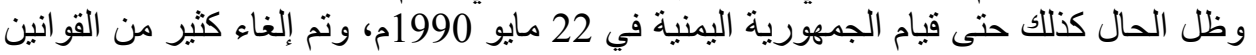

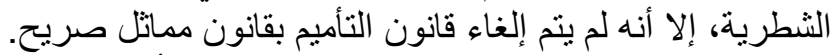

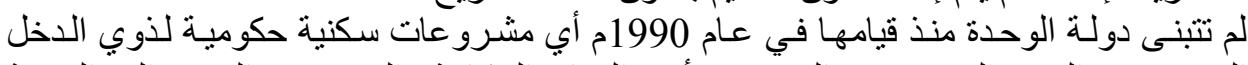

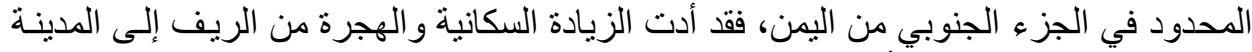

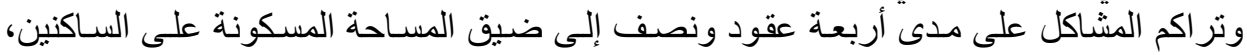

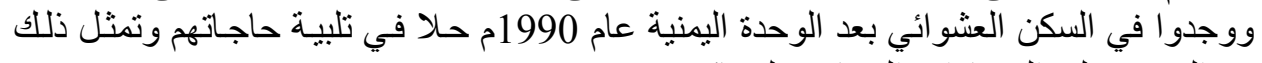

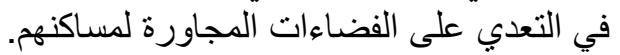

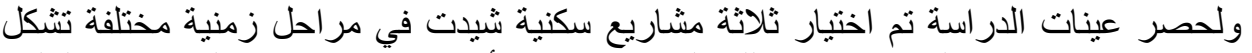

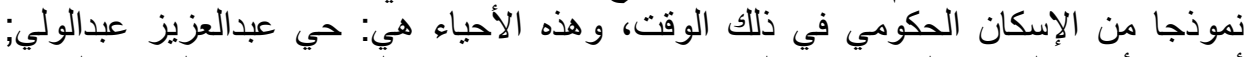

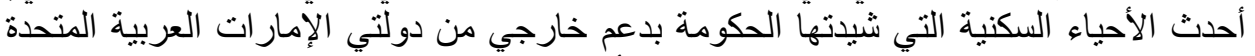

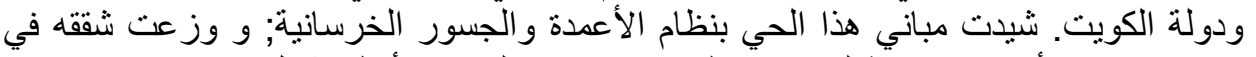

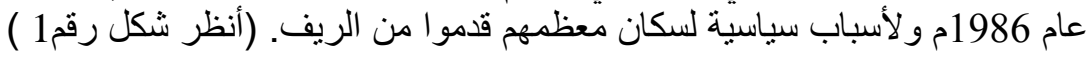


حي نجوى مكاوي و الذي شيدت مبانيه بنظام الوحدات الجاهزة، وأُجرت شققه لمو اطنين من فئات

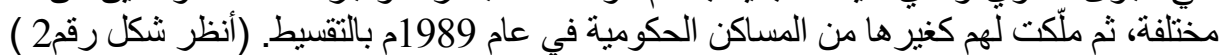

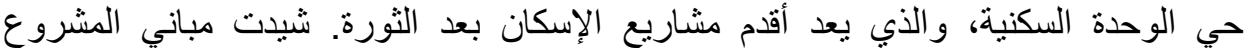

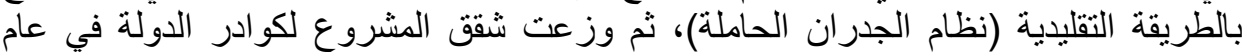

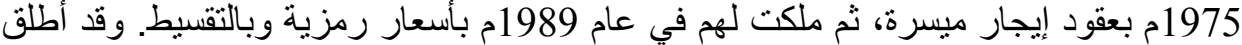
على المشروع الأخير هذه التسمية كونه أول مشروع بنفذ بعد الاستقلال. (أنظر شكل رقم3 فئم )

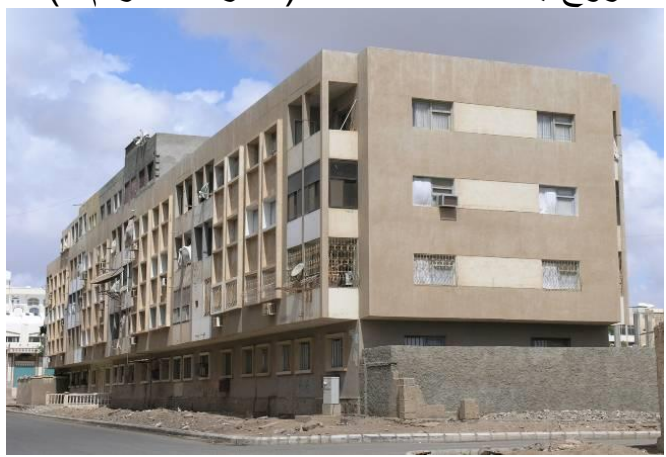
شكل رق1 : صورة تظهر استحداثات على السطوح و على الثار ع العام في حي عبدالعزيز عبدالولي. [1]

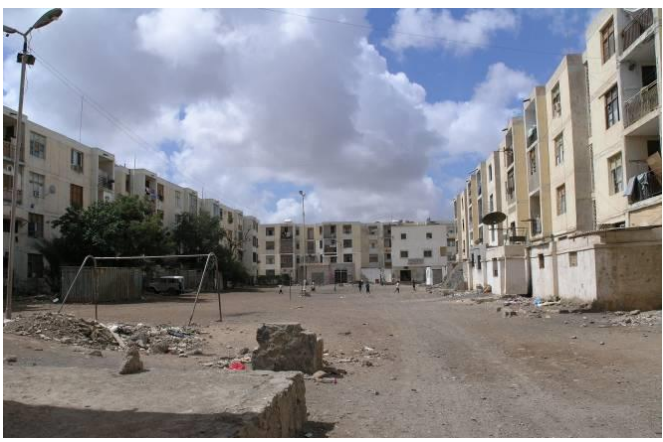

شكل رقم2 : يتكون حي نجوى مكاوي من بلوكات سكنية منر اصة بمسافات بينية

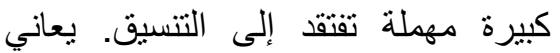
الحي من تعديات على الثار ع العام مسبيًا

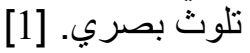

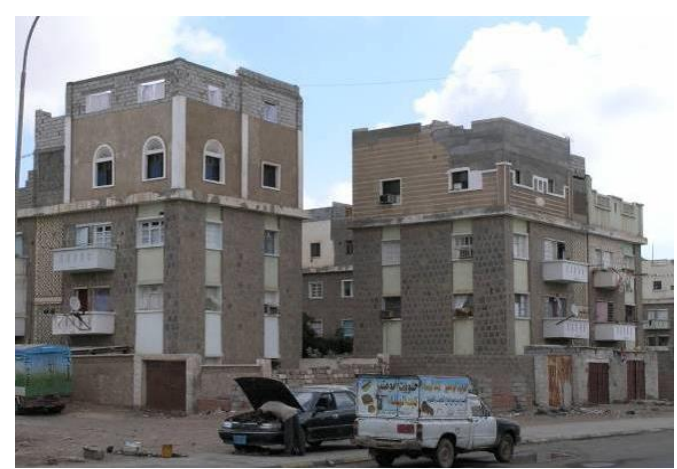

شكل رقم3 : يظهر في الصورة إضافات

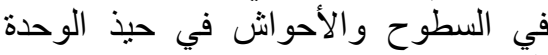
السكنية. [1] 
1-1-4 التحليل المعماري لمشاريع الإسكان في مدينة عدن:

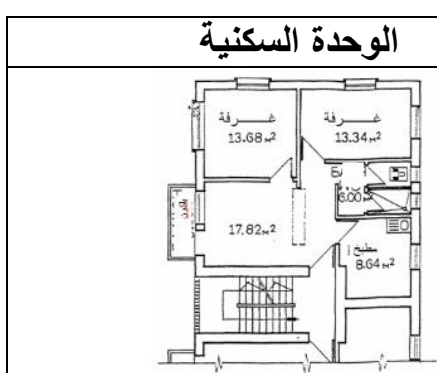

عمار ات نظام قطاعي، تتكون كل عمـارة

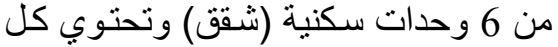

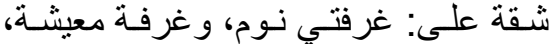

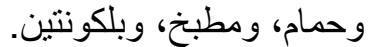

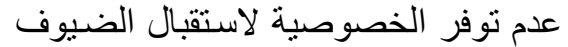

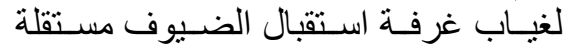

بحمام.

تحويـل وظـائف شـقق الـور الأرضــي إلسى محلات تجارية (إز الة جلر ان وإن إعادة تشطيب).

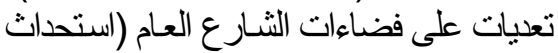

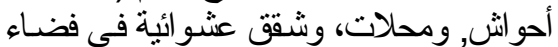
الثنار ع). إضافة أدوار في السطوح.

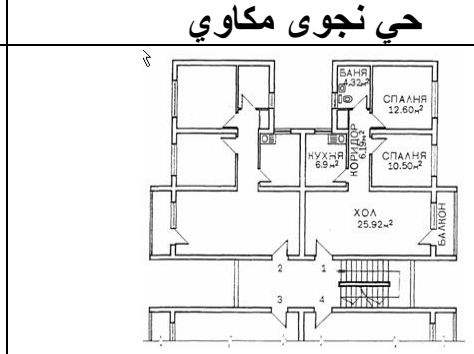

عمـار ات نظام قطاعي، تتكون كل عمـارة

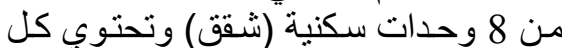

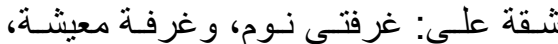
وحمام ومطبخ وبلكونتين.

عدم توفر الخصوصية ودئية لاستقبال الضيوف

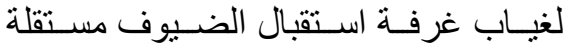

بحمام.

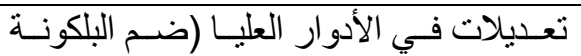

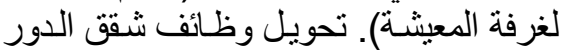
الأرضي إلى محلات تجاريـة (إز الـة جدران

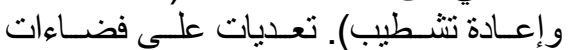

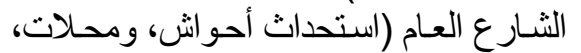

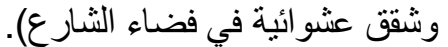

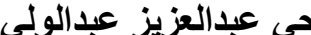

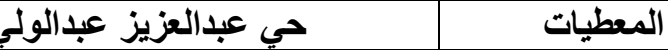

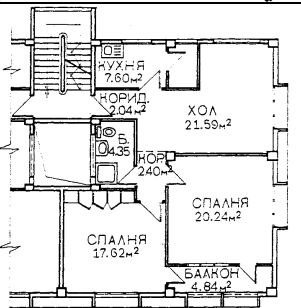

عمار ات نظام قطاعي، تتكون كل عمـارة

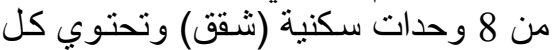

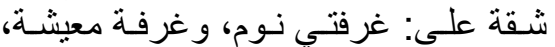
وحمام ومطبخ، وبلكونة وفنتين.

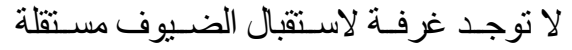

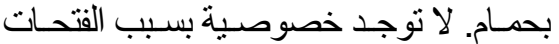

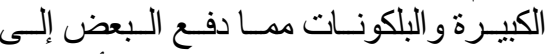

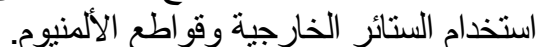

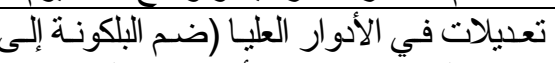

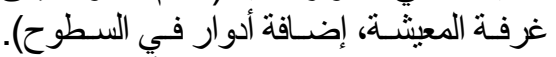

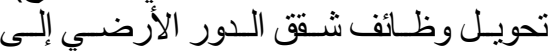
محلات تجارية (إز الة جدران وإعادة لتشئيب).

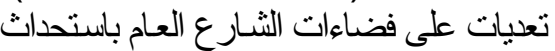
أحواش وشقق عثو ائية فيه.

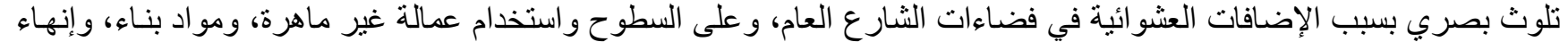

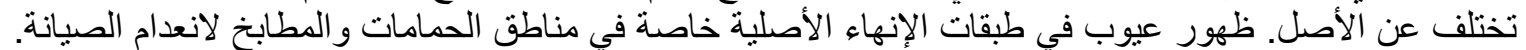

مسقط المبنى السكني (الوحدة السكنية )

التصميم

الخصوصية

التعديلات و التعديات

تلــوث بصـري وبئي 


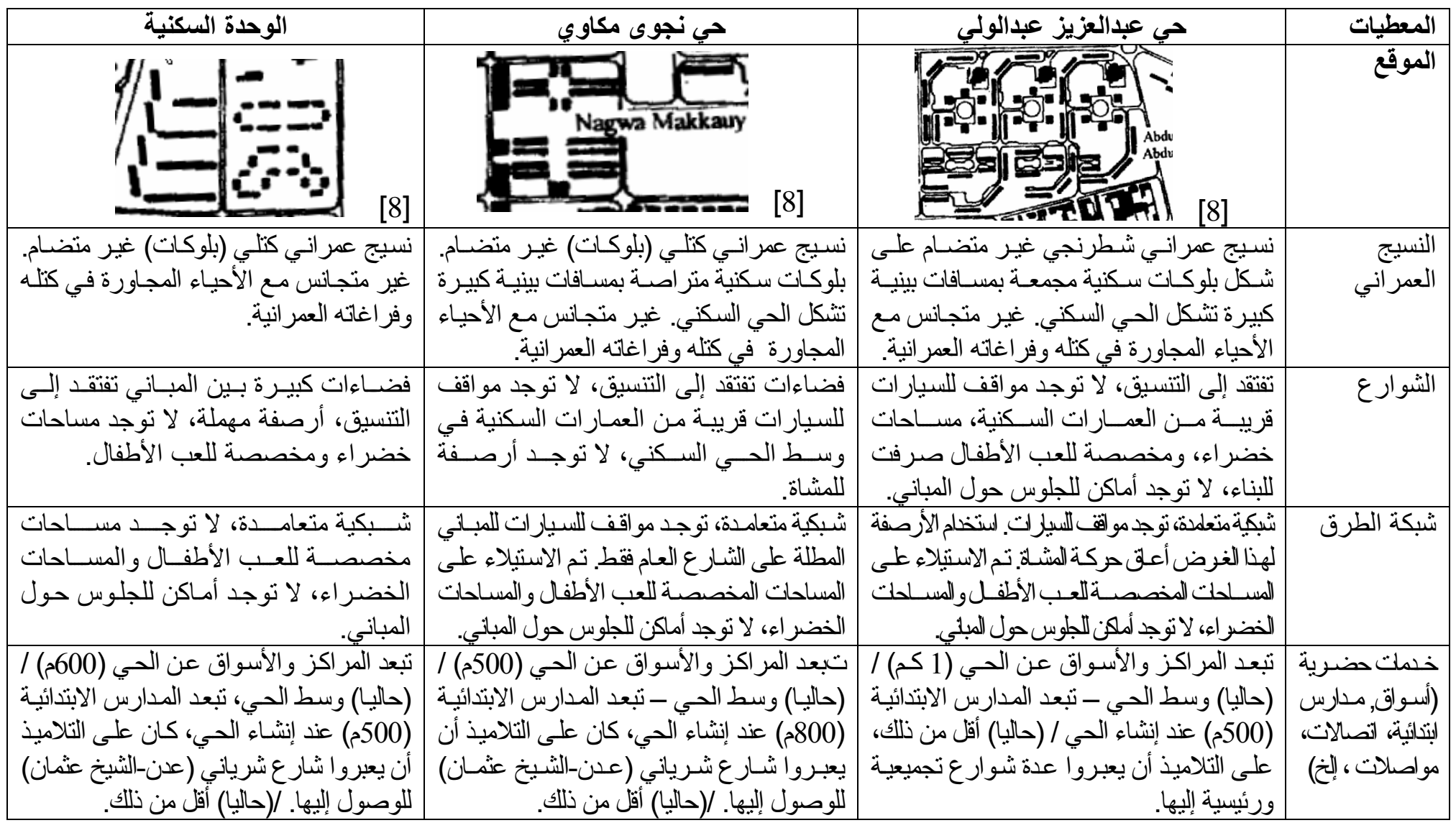




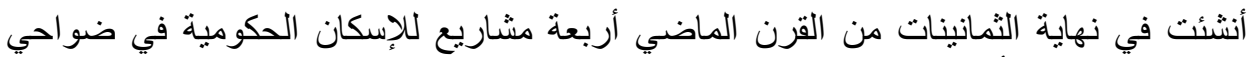

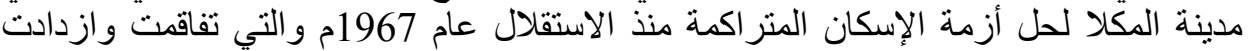

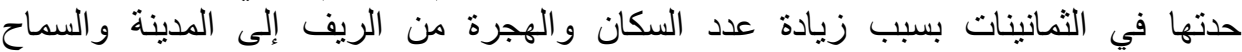

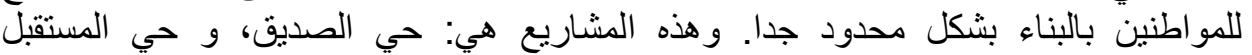

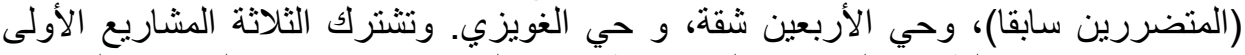
كونها تقع بمحاذاة الطريق الثرياني الذي يربط مدينة المكلا بمدينة عدن (العاصمة الكانة السابقة).

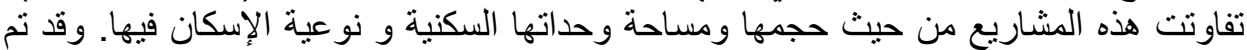
اختبار المشاريع الثناثة الأولى باعتبار ها أكبر المشاريع؛ وتمثل شرائح اجتماعية النية مختلفة ونظم

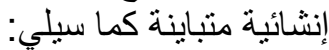

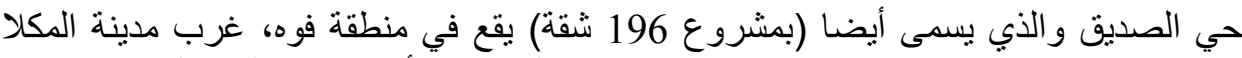

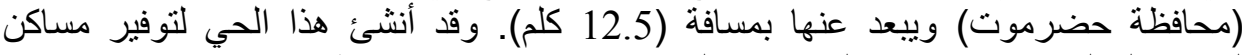

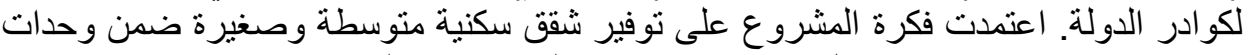

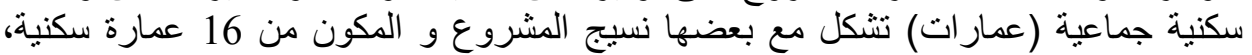

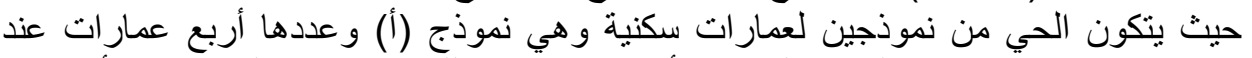

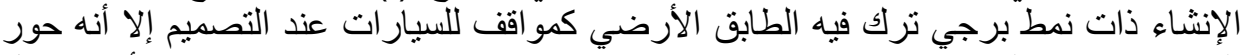

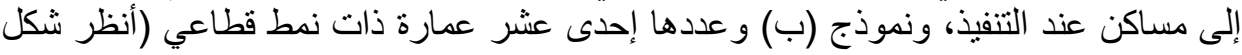

حي المستقبل (منطقة التفات سابقا) ويطلق علية بحي (المتضررين) أيضا، فيقع بفوة في الجهة النية

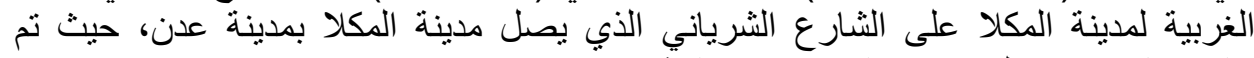

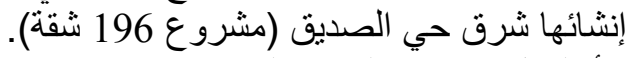

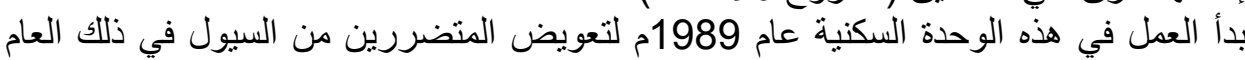

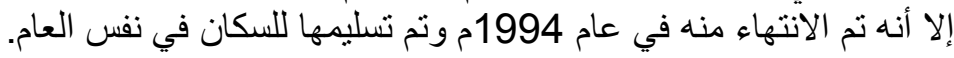

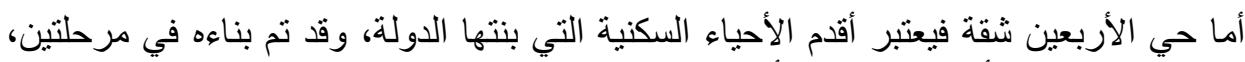

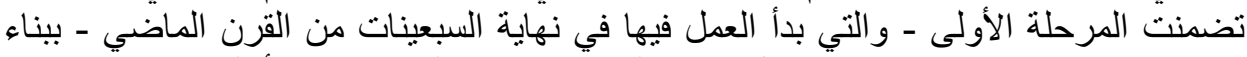

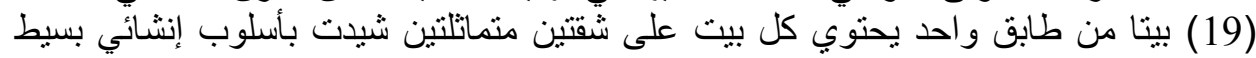

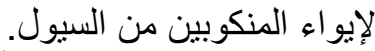

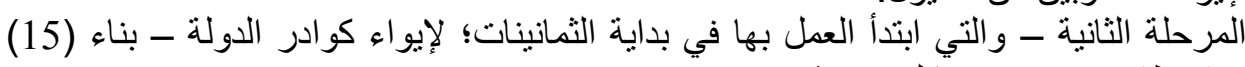

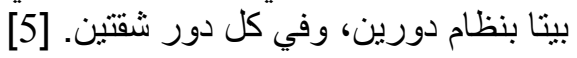

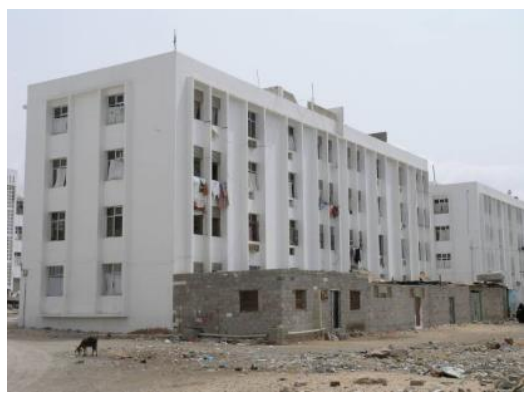

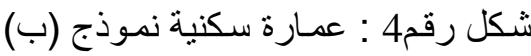

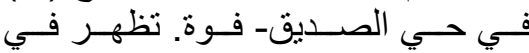

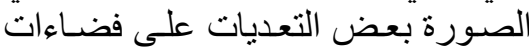

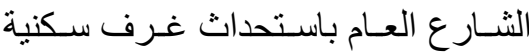

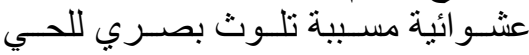

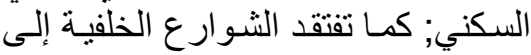

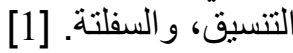


1-2-4 التحليل المعماري لمشاريع الإسكان في مدينة المكلا:

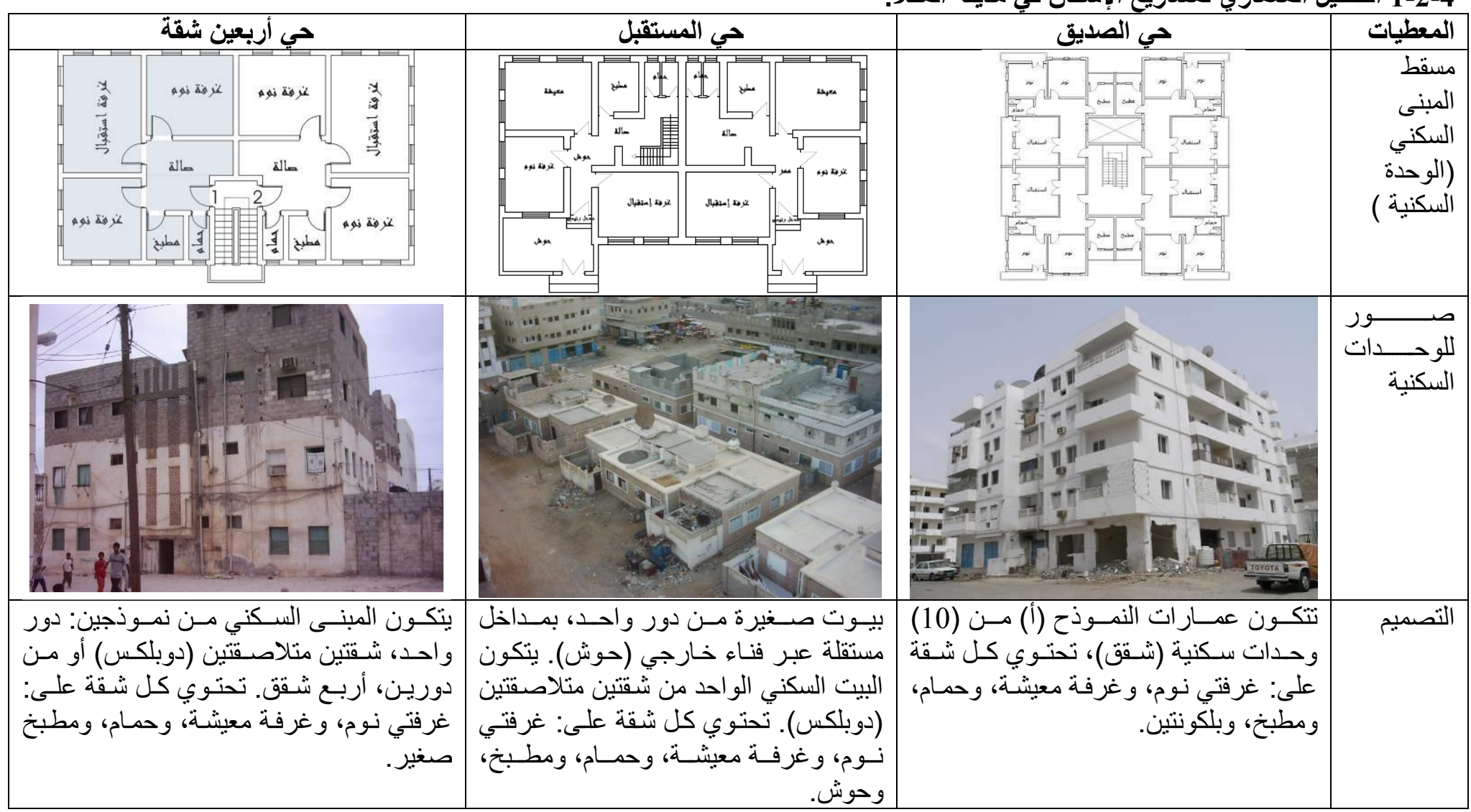




\begin{tabular}{|c|c|c|c|}
\hline حي أربعين شقة & حي المستقبل & حي الصديق & المعطيات \\
\hline 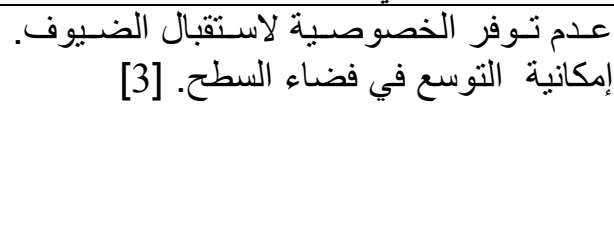 & 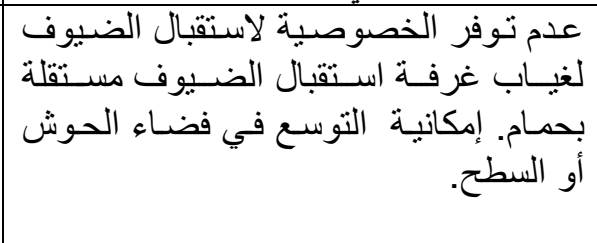 & 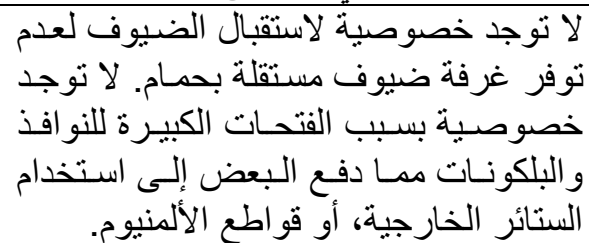 & الخصوصية \\
\hline 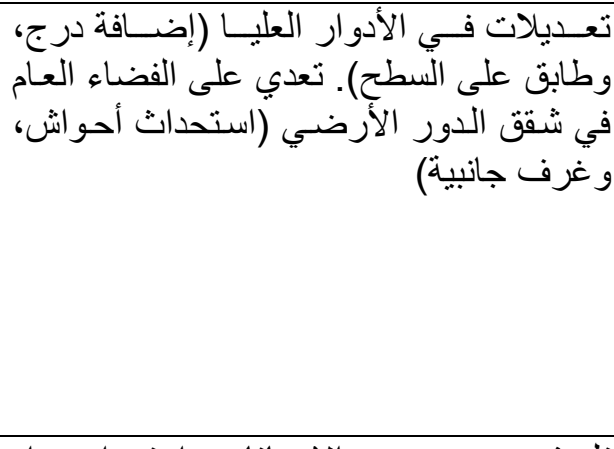 & 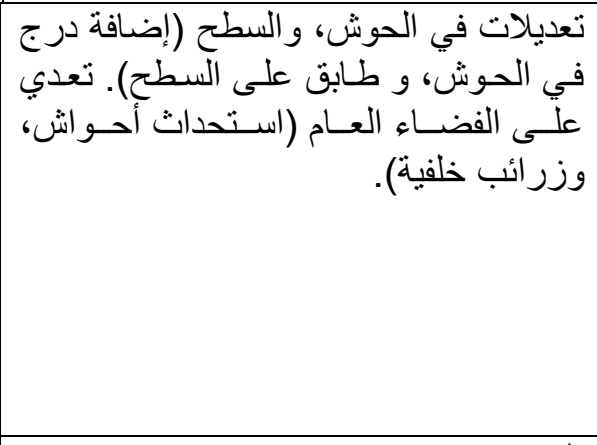 & 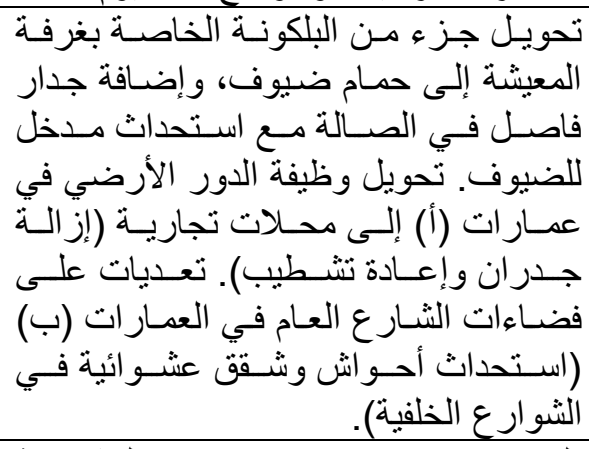 & و التعديلات \\
\hline 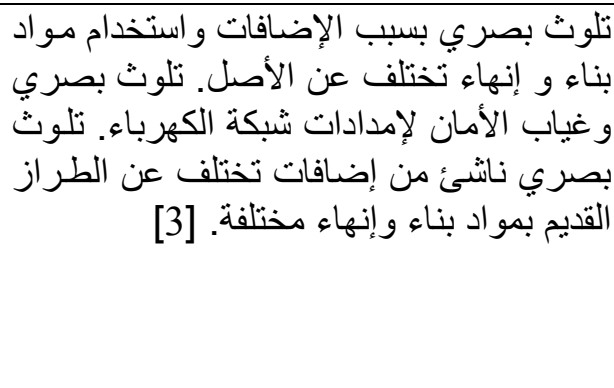 & 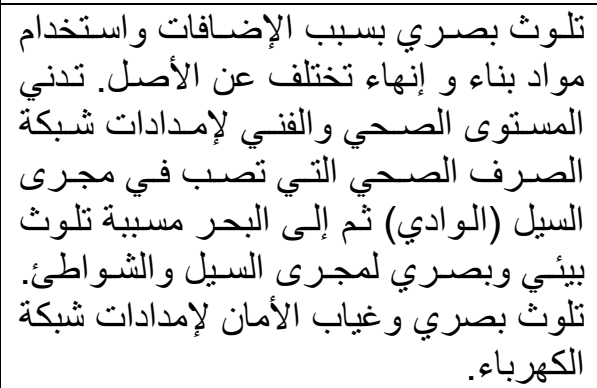 & 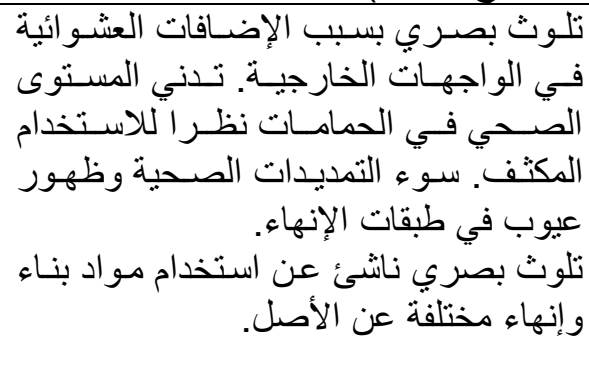 & والبئئي \\
\hline
\end{tabular}


2-2-4 التحليل العمراني لمشاريع الإسكان في مدينة المكلا:

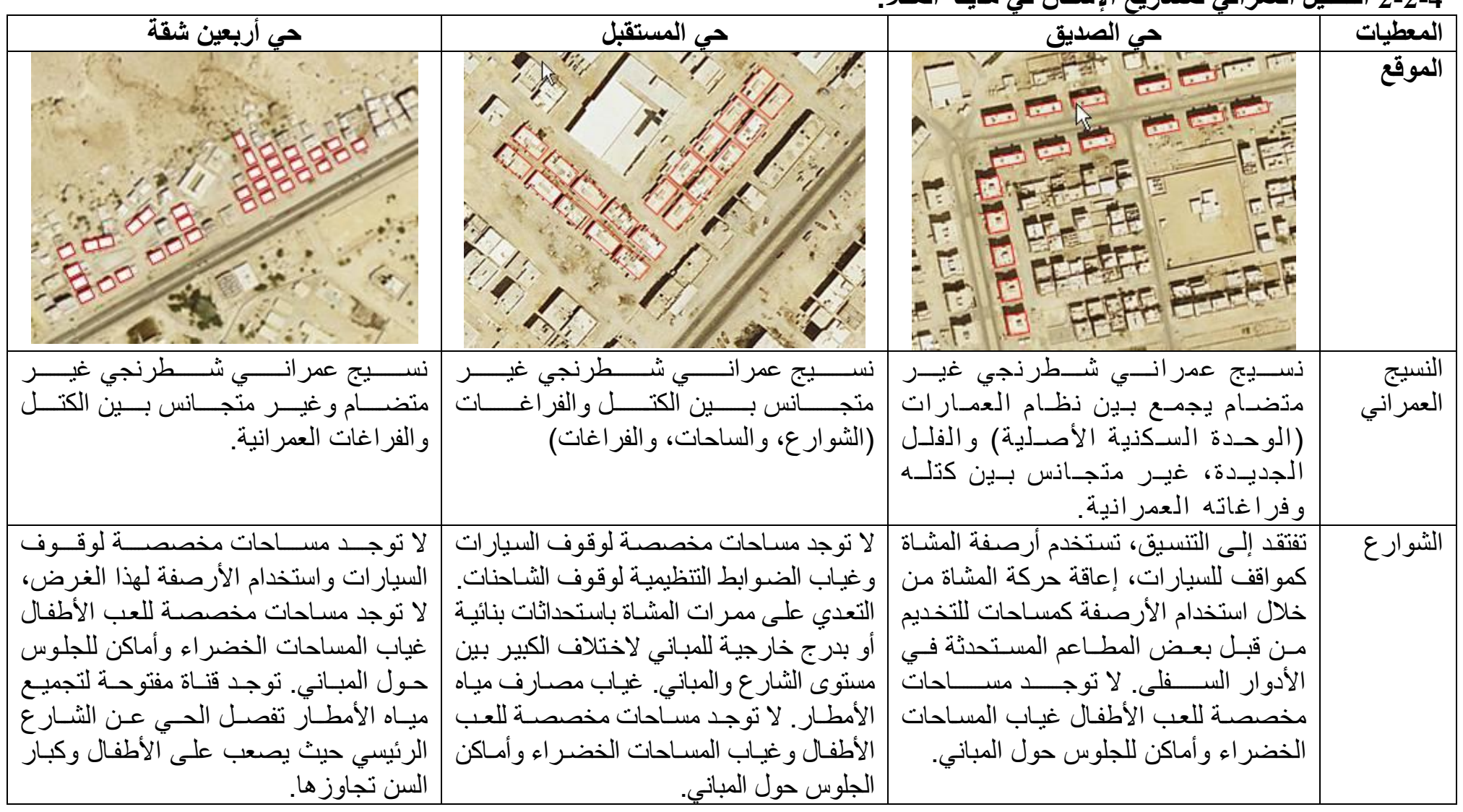




\begin{tabular}{|c|c|c|c|}
\hline حي أربعين شقة & حي المستقبل & حي الصديق & المعطيات \\
\hline 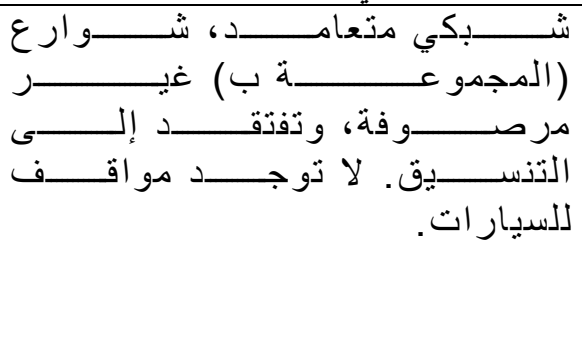 & 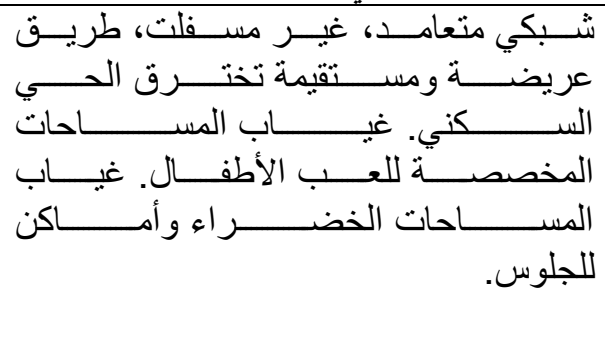 & 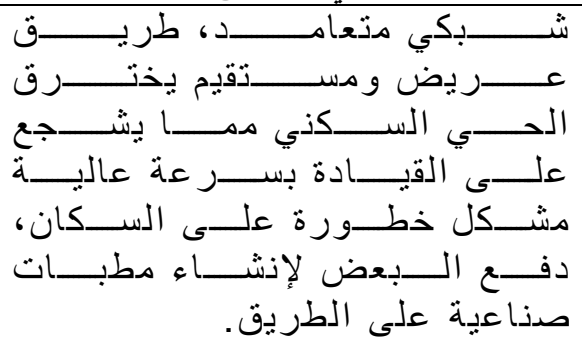 & 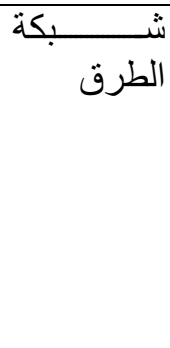 \\
\hline 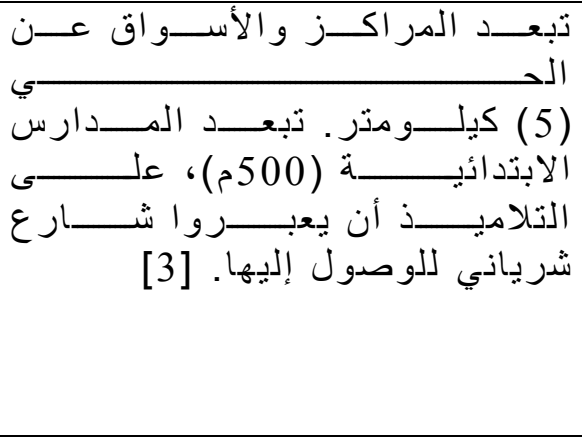 & 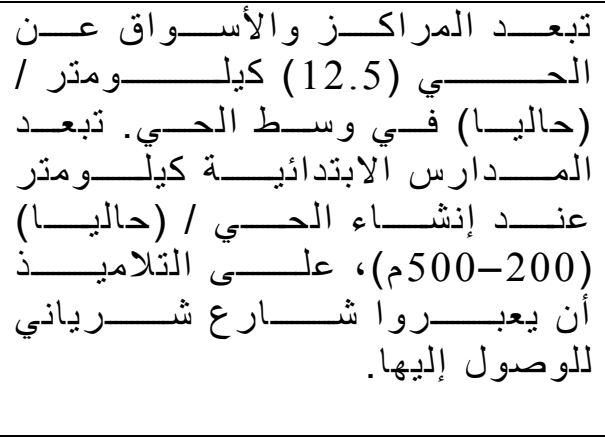 & 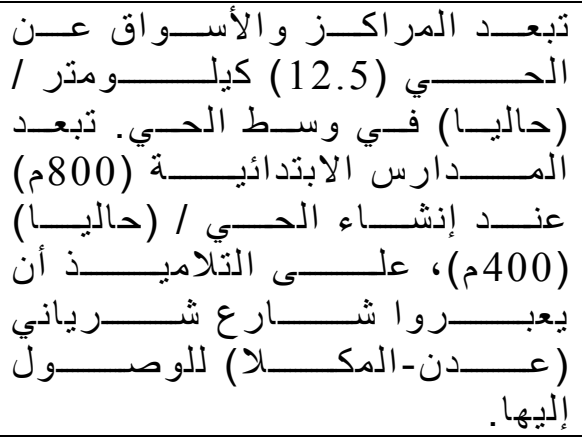 & 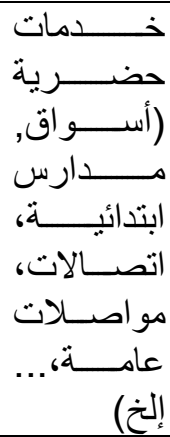 \\
\hline
\end{tabular}




\section{5- خلاصة مناقشة الدراسة التحليلية:}

نستنتج من خلال الدر اسة التحليلية المقارنة لأنماط من البناء التقليدي و لأحياء سكنية مختارة لمدينتي

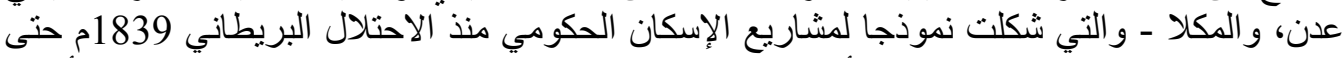

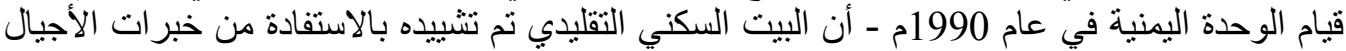

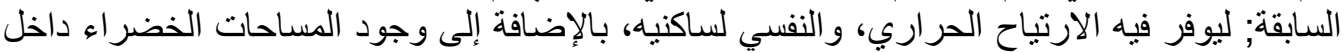

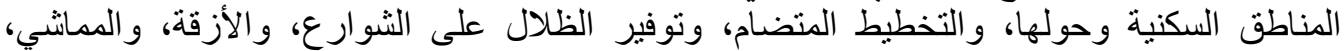

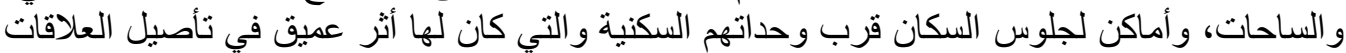

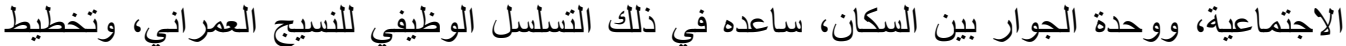

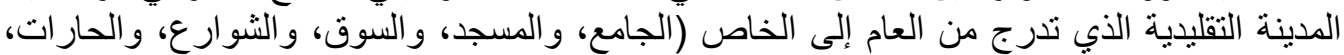
والأزقة، ثم البيوت). أما على الصعيد الاجتماعي فقد صمم البيت ليلبي محتاجات الأسرة في استقبال

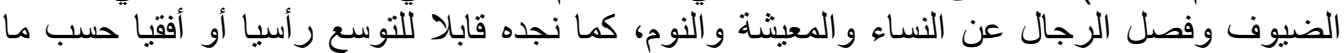
تقتضيه الظروف وف وفئ الحاجة. أما من حيث نماذج الإسكان الحكومية فنجدها تشترك فيما بينها بعدة عو امل يمكن إيجاز ها بالتالي:

\section{1-5 ع 1-5 امل تخطيطية:}

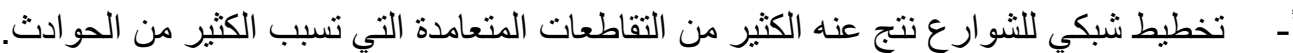

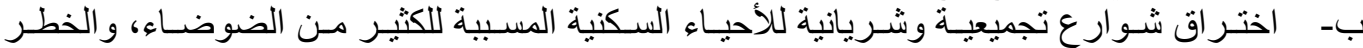

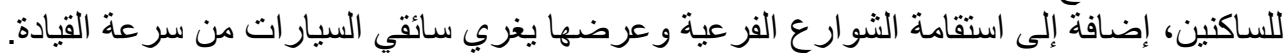
عدم التدرج الوظيفي على مستوى الأحياء السكنية بطريقة مدروسة جعل السكان يشعرون بالغربـة،

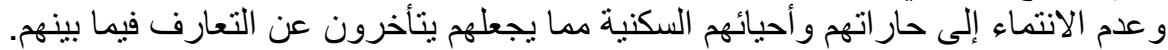

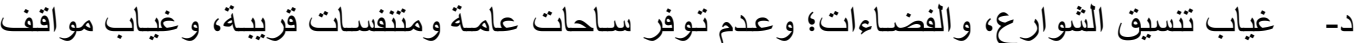

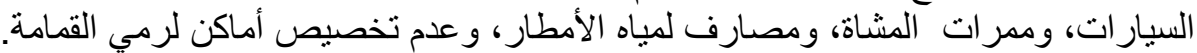

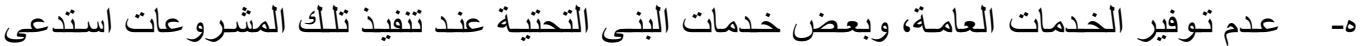

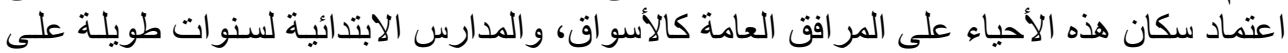

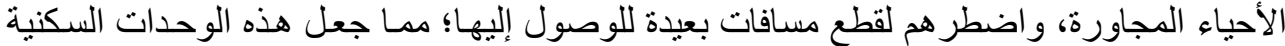
تشكل عنصر طرد لسنوات طوريلة.

2-5 2-5 عوامل تصميمية: أـ فذت مشـاريع الإسكان الحكومية منذ الاحتلال البريطاني حتى الاستقلال الوطني (توجه اشتر اكي)

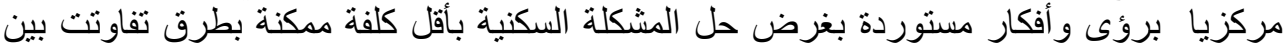

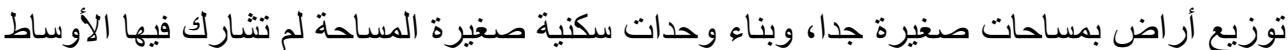
الثعبية المستفيدة في أي مرحلة من مر احل اتخاذ القر ار ، كلاهما لمات لم يلبي احتياجات السكان.

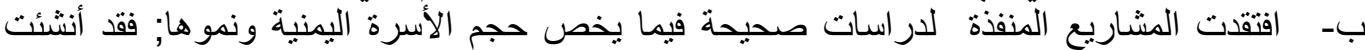

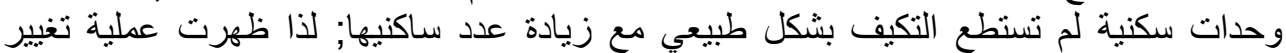

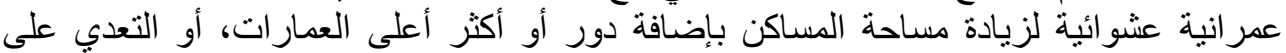

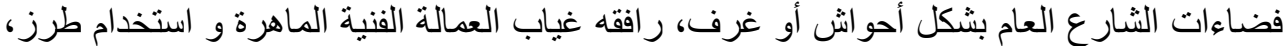

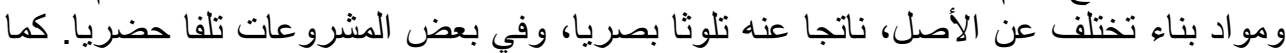

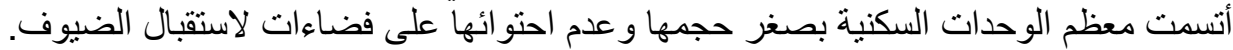

3-5 كان لغياب البعد الاجتماعي أثناء تصميم هذه المباعي المئي دورا في ظهور مشاكل أسرية فسكان هذه

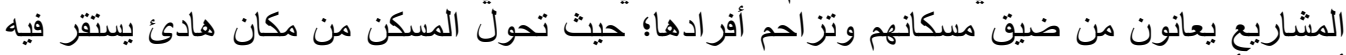
أفر اد الأسرة إلى مكان مكدس يشعرون فيه بالضيق و الضوضاء، وفقدان الخصوصية، وقد دفع ذلك 
كثير إ من سكان مشاريع العمارات ـ القادرين ماديا بعد الانفتاح الاقتصادي في عام 1990- للانتقال

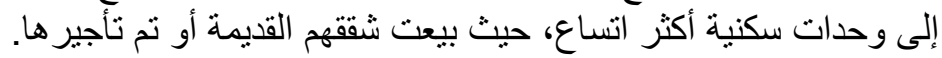

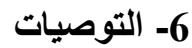

مما لا شك فيه أن على الدولة بمؤسساتها ووز اراتها المعنية أن يكون لها دور في توفير المسكن الميسر

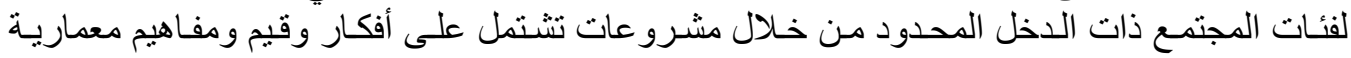

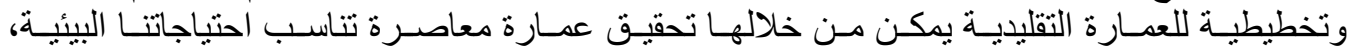

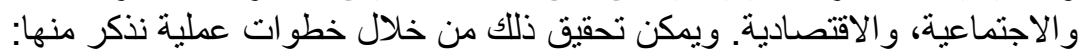

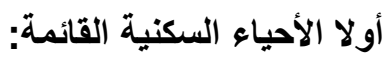

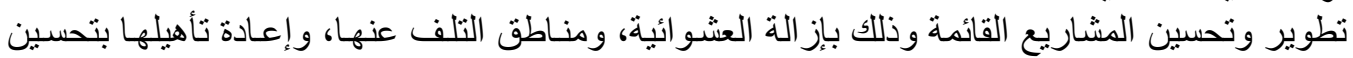

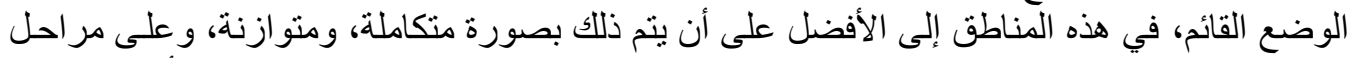

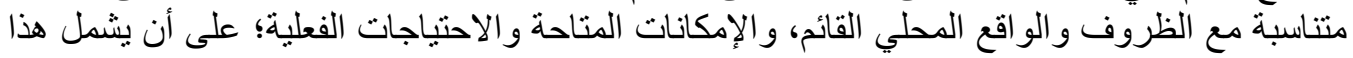

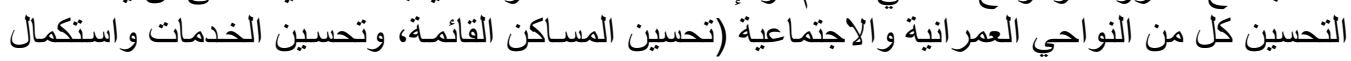

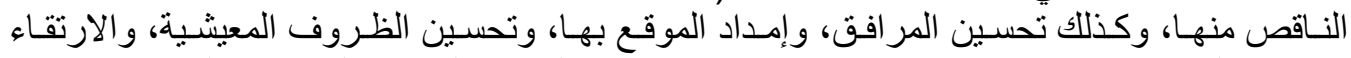

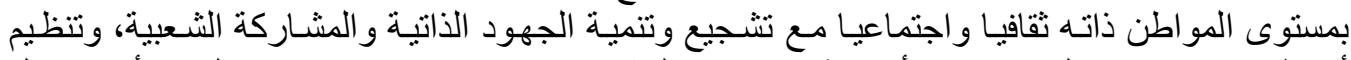

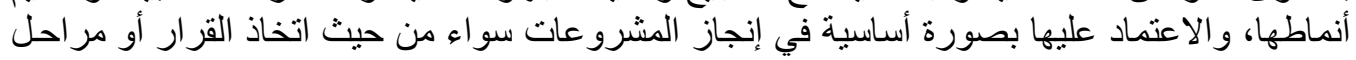
التنفيذ، وذللك لضمان ديمونها).

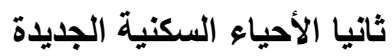

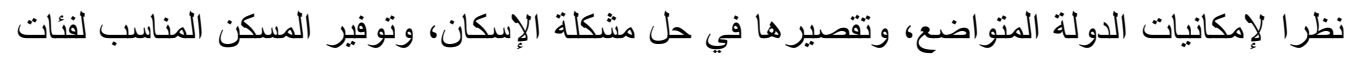

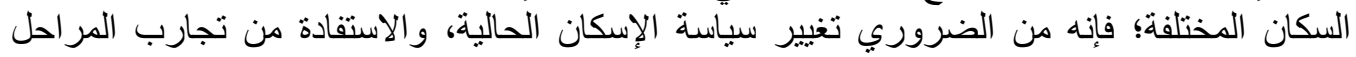

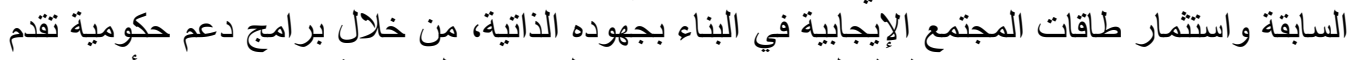

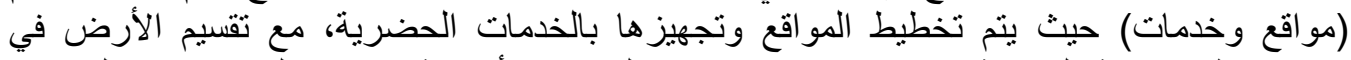

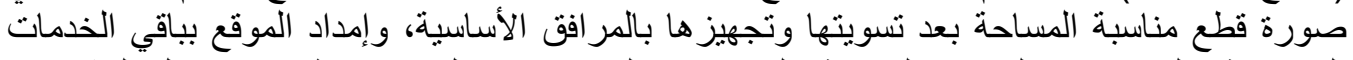

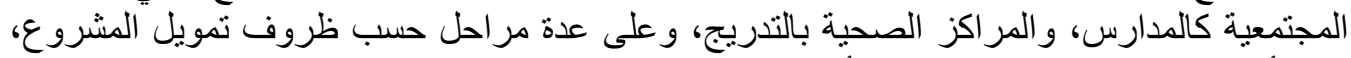

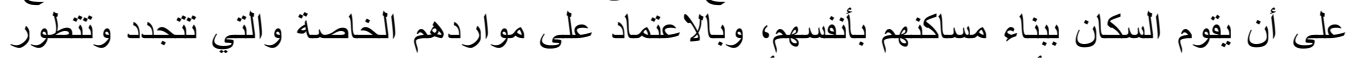

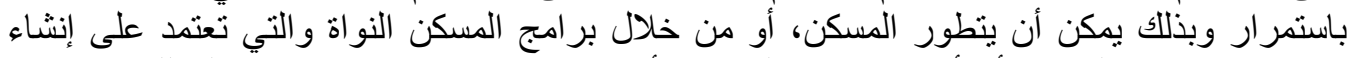

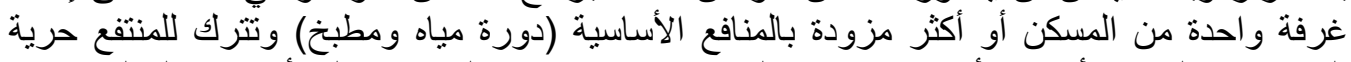

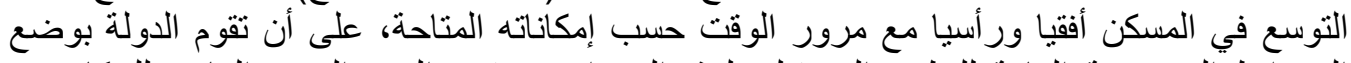

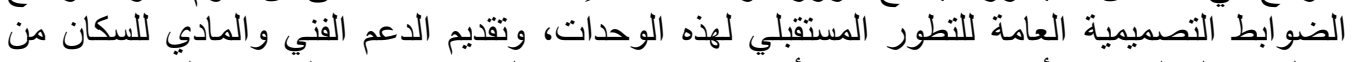

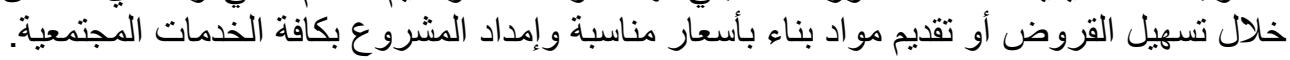

$$
\text { 7 [- المراجع }
$$

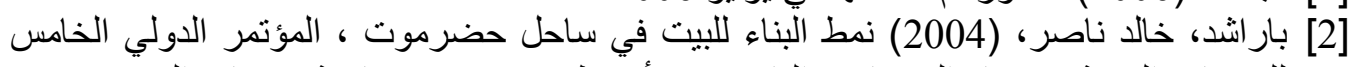

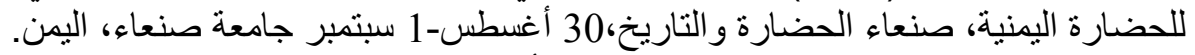

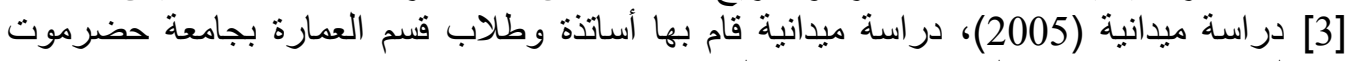

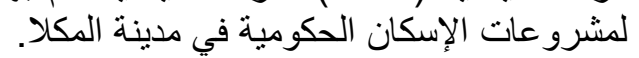

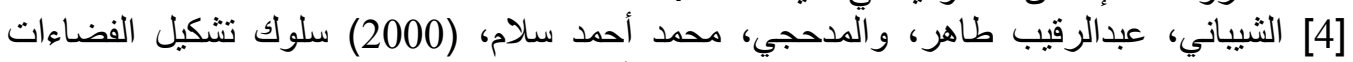

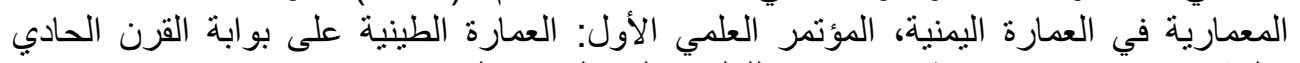

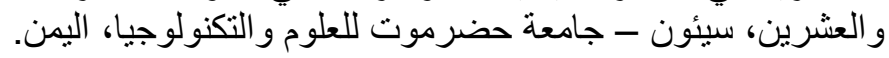

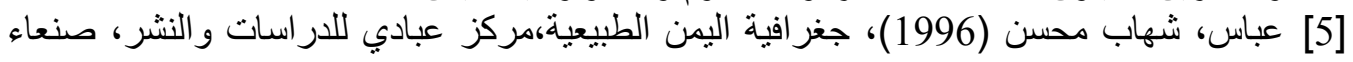


[6] القادري، عبدالناصر (1999)، مورفولوجيا العمارة اليمنية، رسالة ماجستير غير منشورة، قسم الهندسة المعمارية كلية الهندسة جامعة بغدادي،

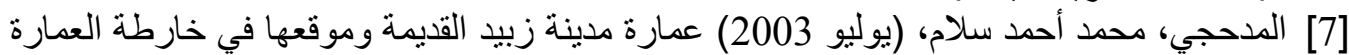

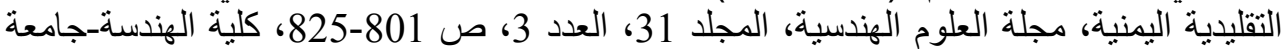
أسيوط-مصر.

[8] Barashed, Khaled (1997), Historische Untersuchng zur Stadt Aden als Grundlage fuer Ihre zukuenftige Gestaltuung, Dissertation, Bauhaus Universitaet Weimar, Germany, pp 105-138.

[9] Varanda, Fernando. (1982), Art of Building in Yemen, The MIT Press, Cambridge, Massachusetts, London, England, pp 100-131.

[10] Mukalla Master Plan 1981-2011, (1982),Arab Institute for Design and Studies, Beirut, pp 87-186. 